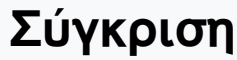

Tóp. 18 (2007)

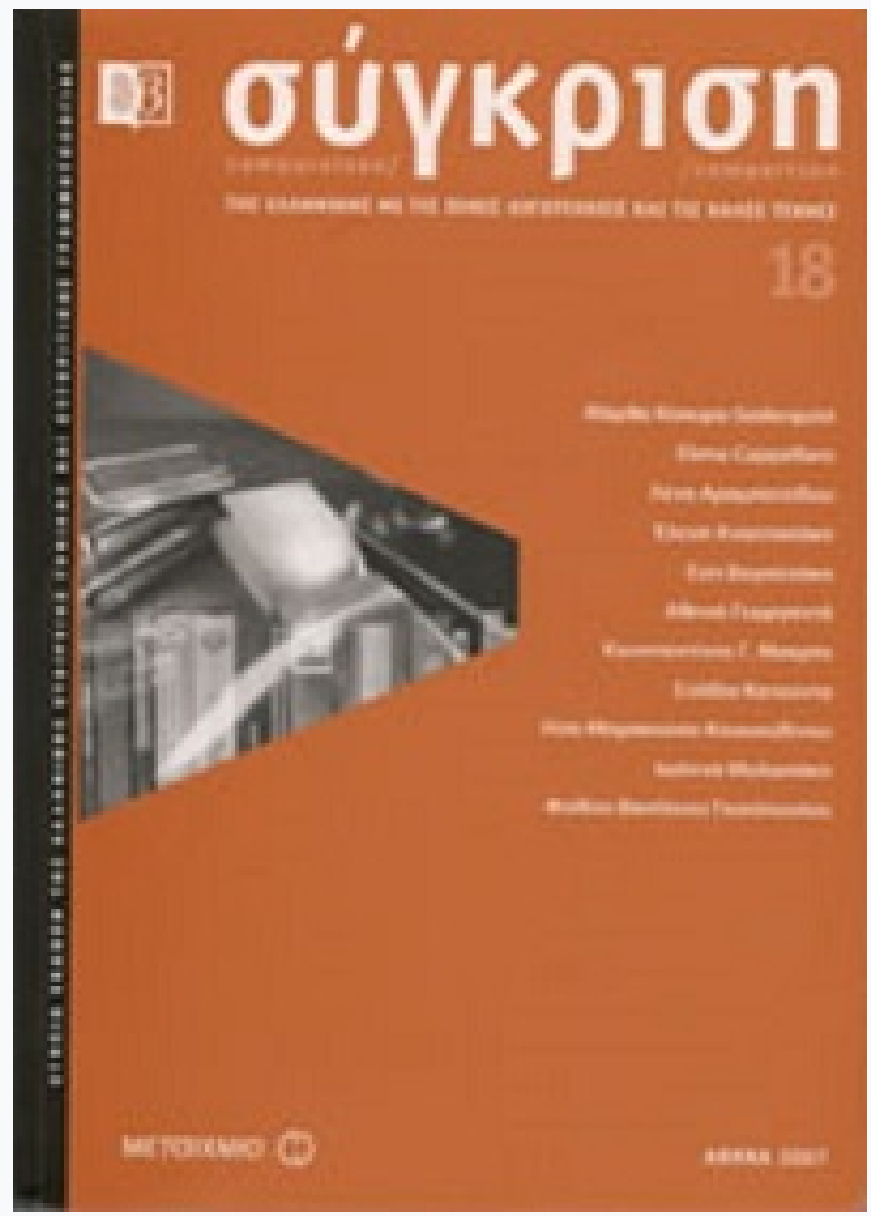

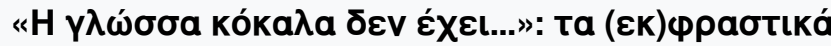

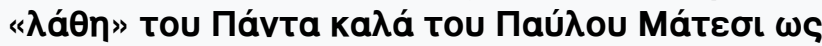

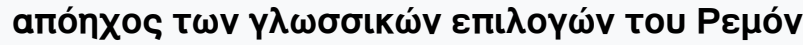

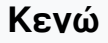

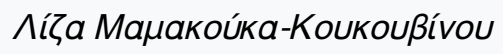

doi: $\underline{10.12681 / \text { comparison.10316 }}$

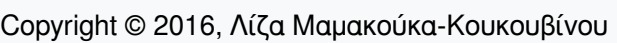

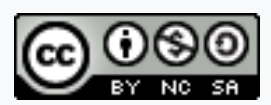

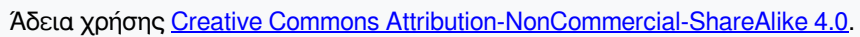

\section{Bıß入ıоррачıкń avaчopá:}

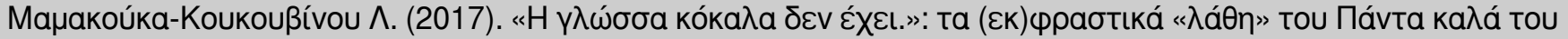

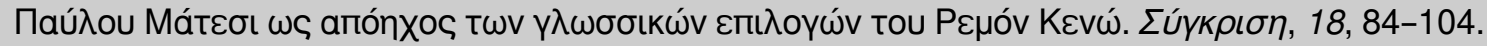

https://doi.org/10.12681/comparison.10316 


\title{
AIZA MAMAKOYKA-KOYKOYBINOY
}

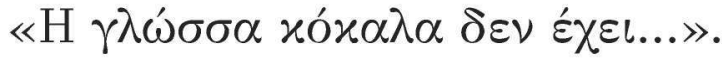

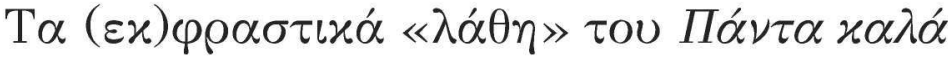

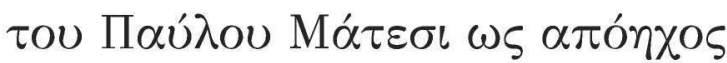

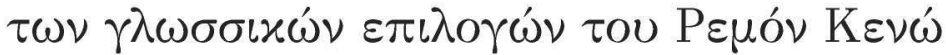

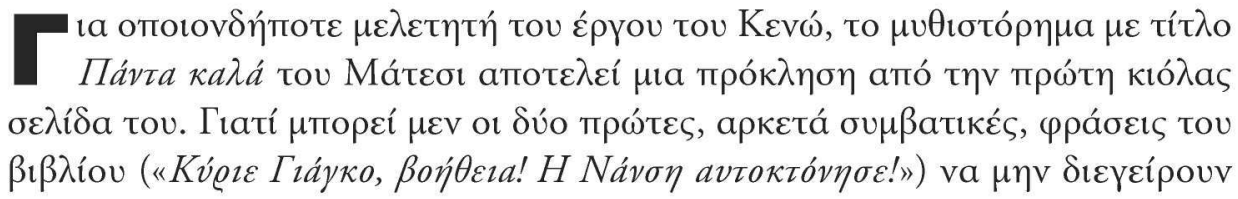

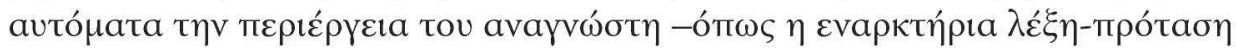

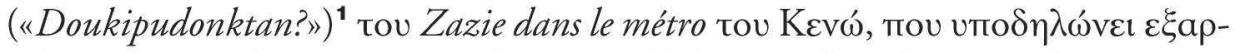

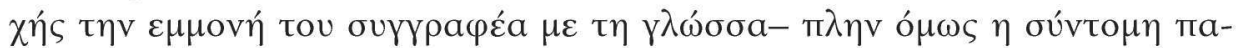

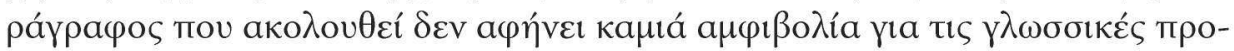

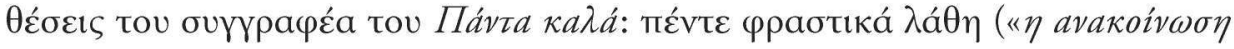

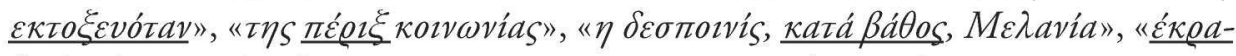

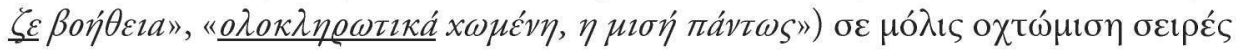

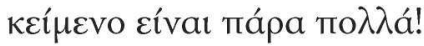

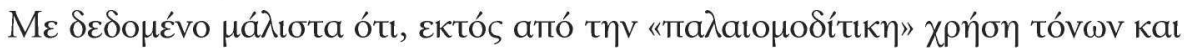

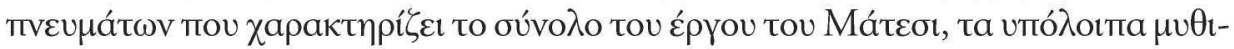

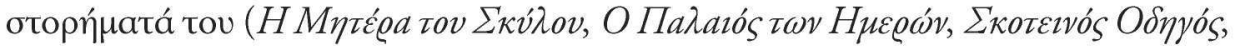

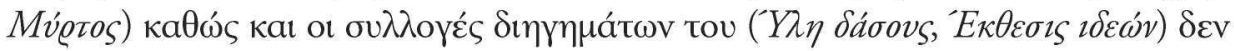

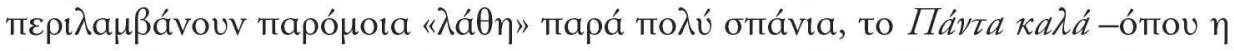

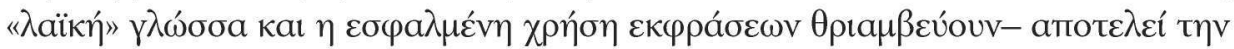

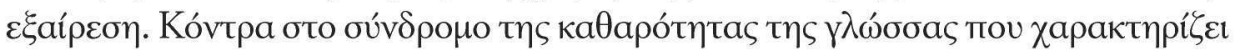

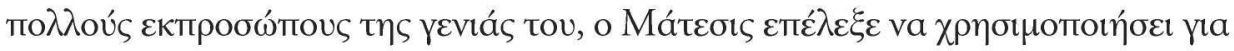

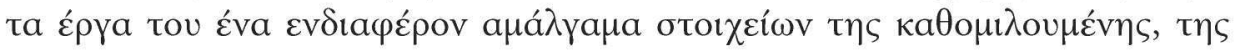

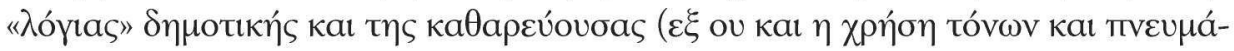

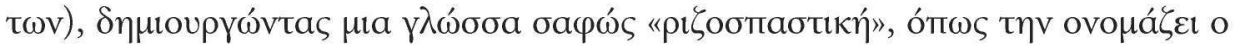

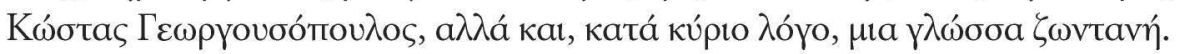

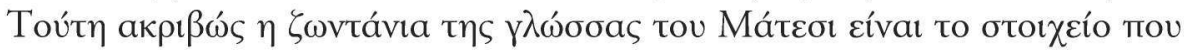

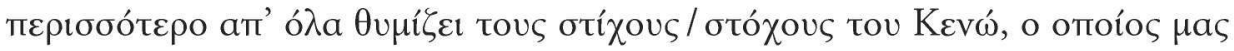
протре́пвเ: 
Prends ces mots dans tes mains et sens leurs pieds agiles et sens leur cour qui bat ${ }^{2}$ comme celui du chien [...].

Prends ces mots dans tes mains et vois comme ils sont faits. ${ }^{3}$

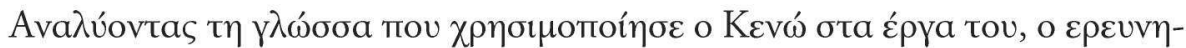

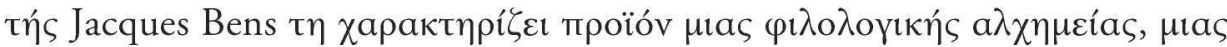

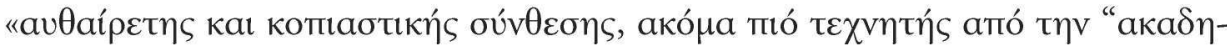

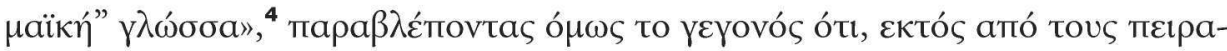

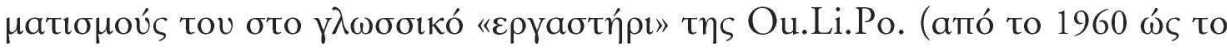

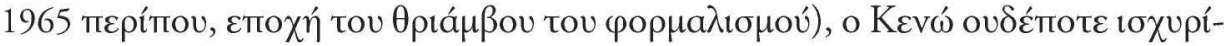

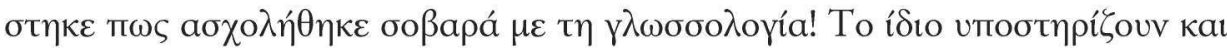

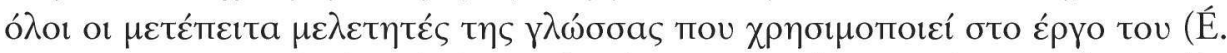
Beaumatin, Jean-Charles Chabanne, ${ }^{\mathbf{5}}$ Val Panaitescu, ${ }^{\mathbf{6}}$ Anne Clancier, É. Lesaffre

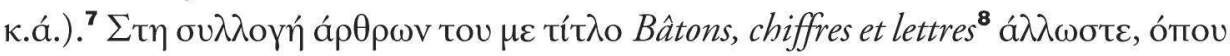

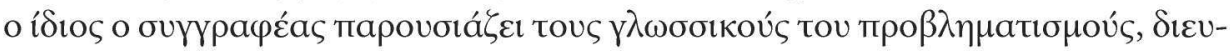

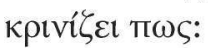

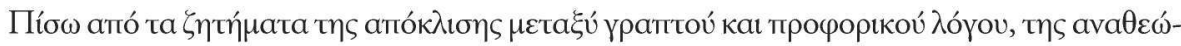

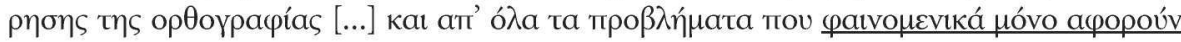

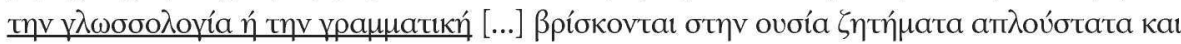

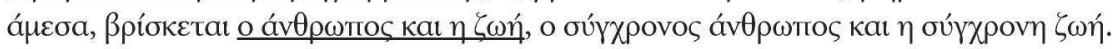

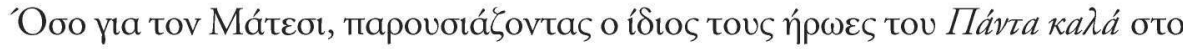

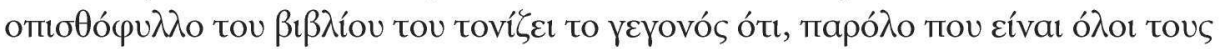

[...] áoт

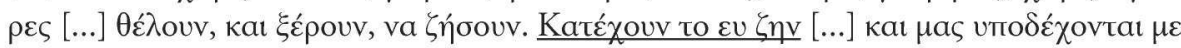

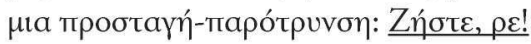

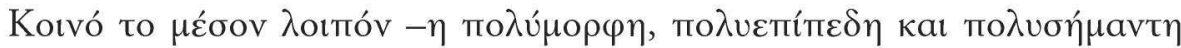

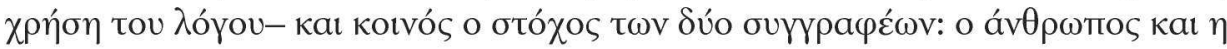

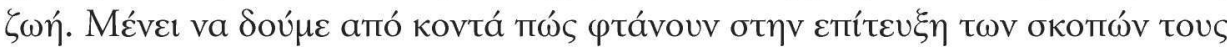

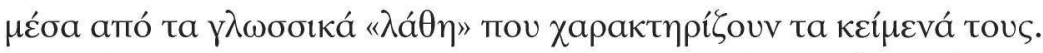

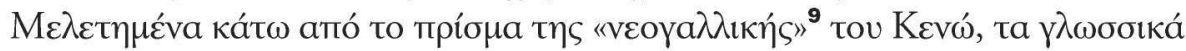

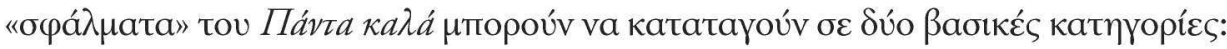

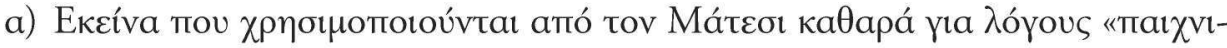

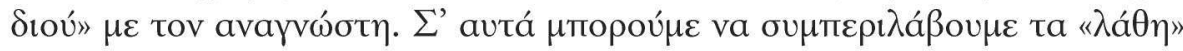

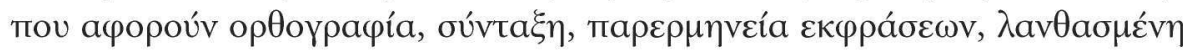

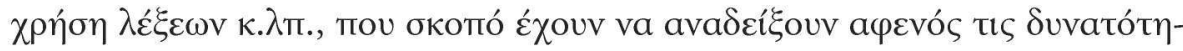

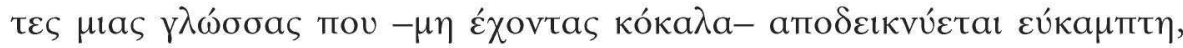

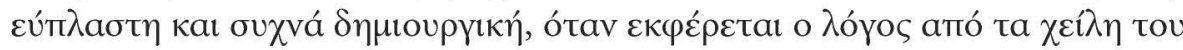




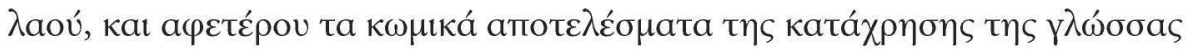

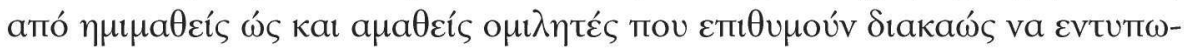

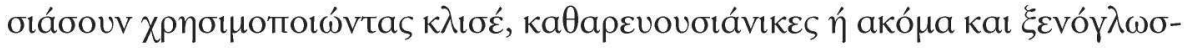

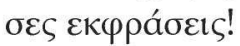

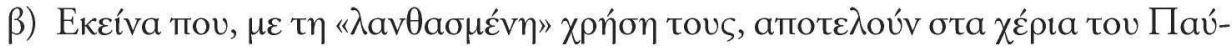

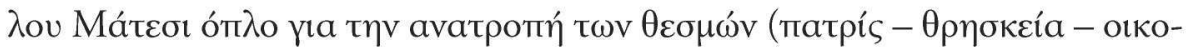

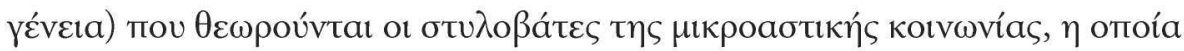

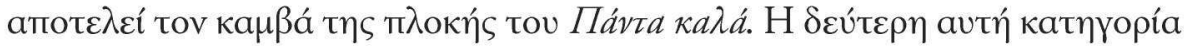

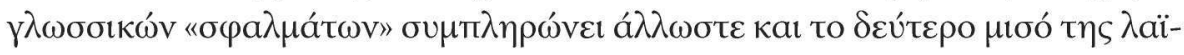

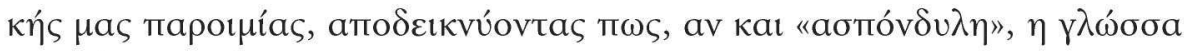

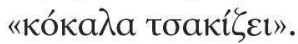

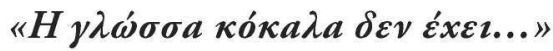

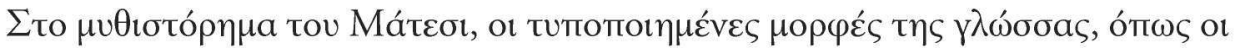

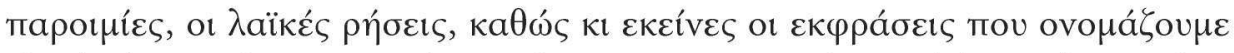

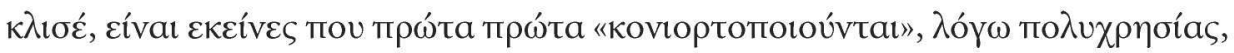

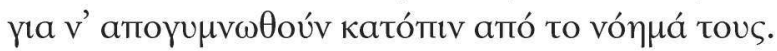

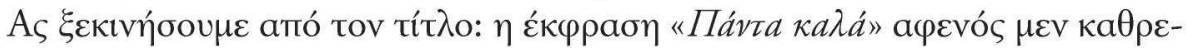

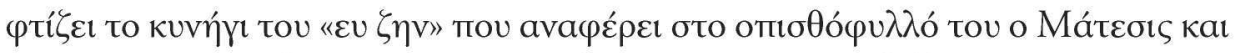

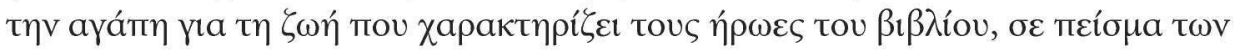

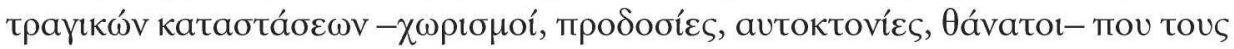

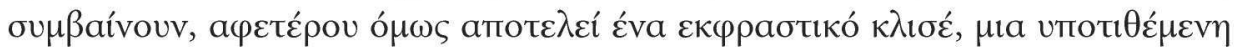

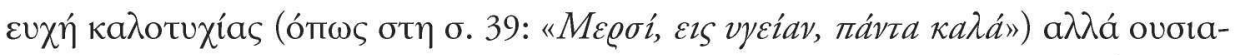

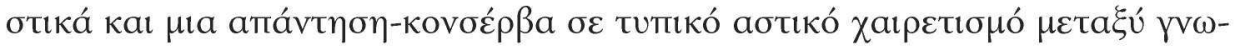

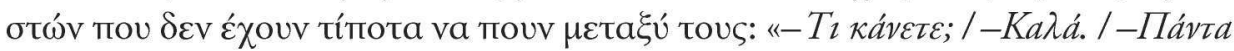

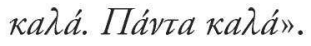

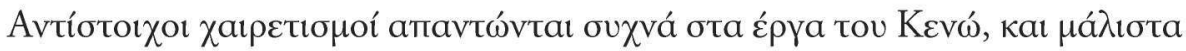

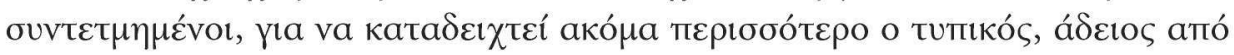

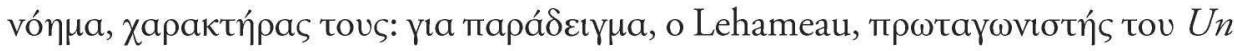

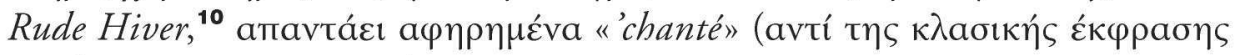

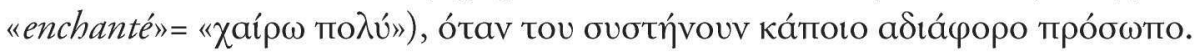

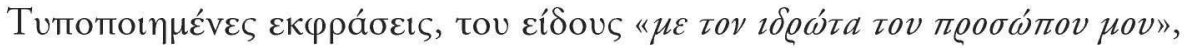

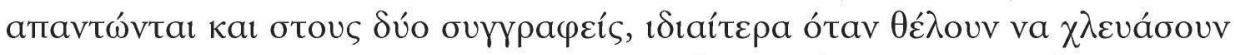

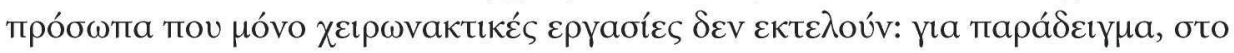

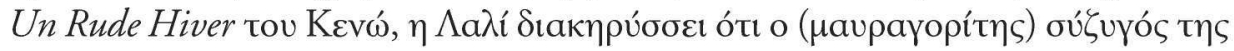

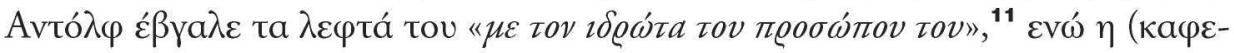




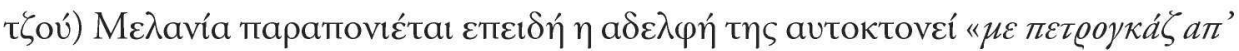

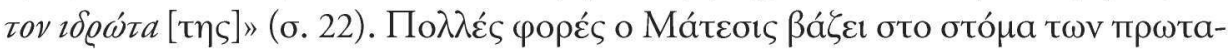

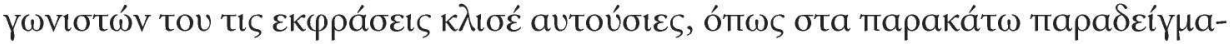

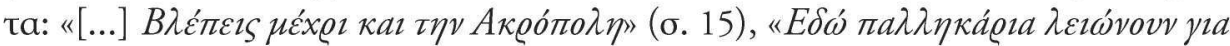

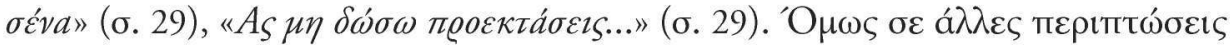

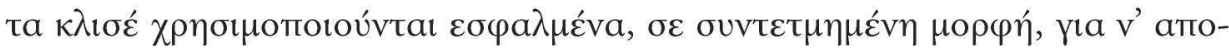

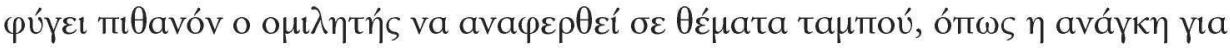
тоva

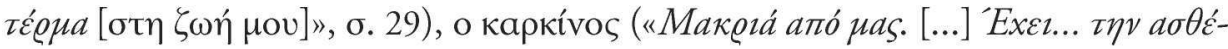

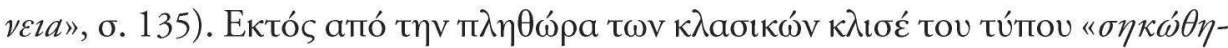

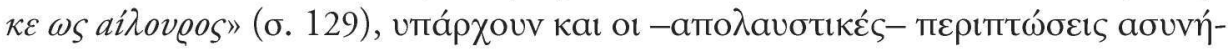

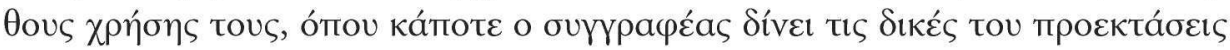

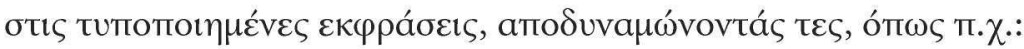

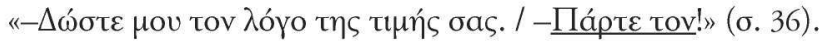

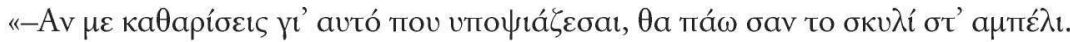

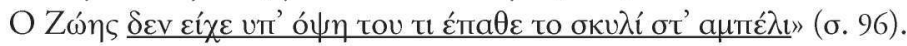

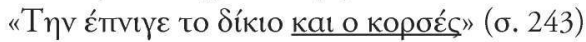

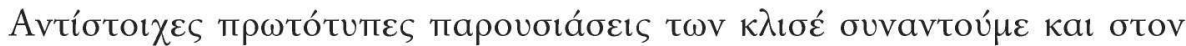

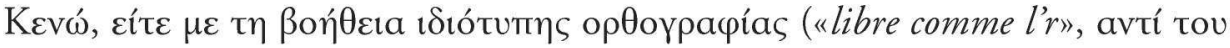

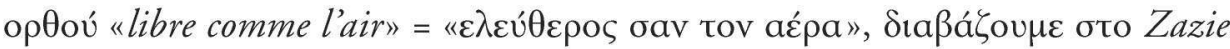

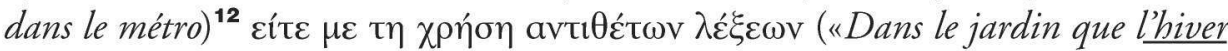

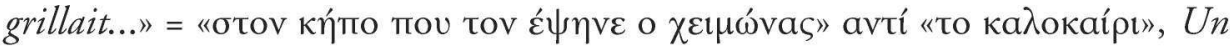

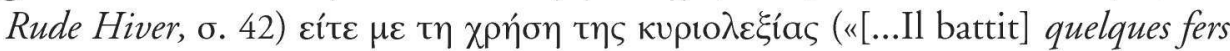

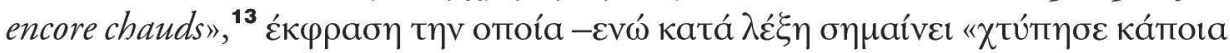

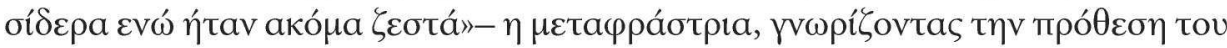

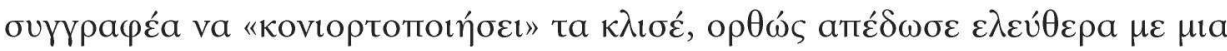

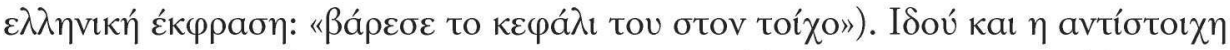

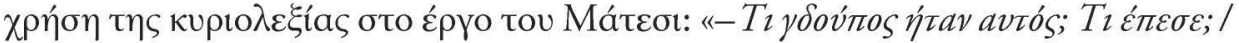

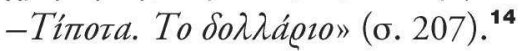

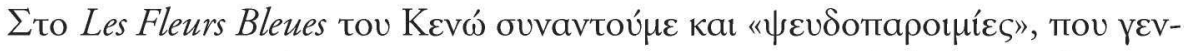

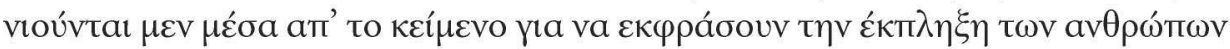

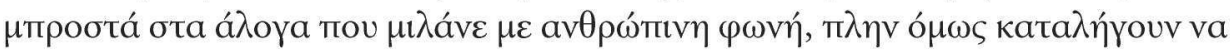

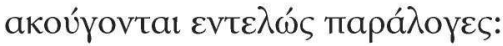

"Animal qu’a parlé, âme damnée», "Si le coq a ri tôt, l'haricot pue trop", "Quand l'huître a causé, l'huis est très cassé», «A poisson qui cause, petit cochon peu rose», «Si bêle le zèbre ut, voilà Belzébuth» (Les Fleurs Bleues, o. 34-35). 


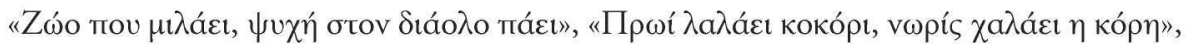

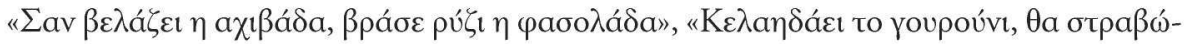

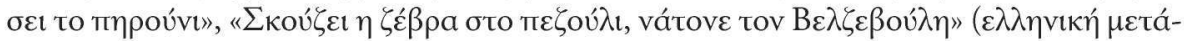

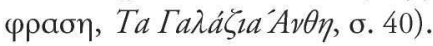

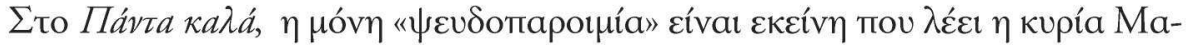

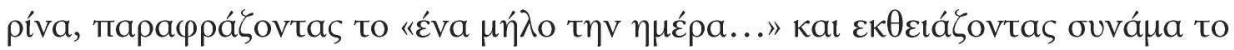

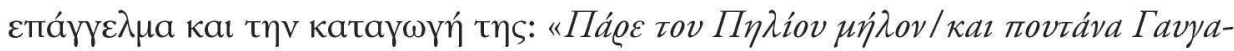
$\mu \eta \dot{\lambda} \omega \eta \gg$ (о. 203).

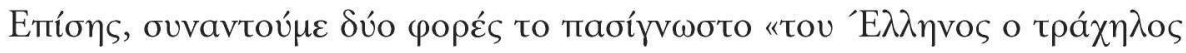

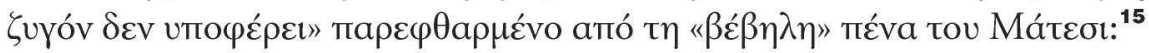

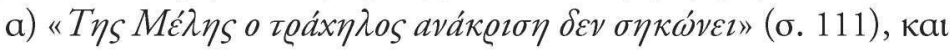

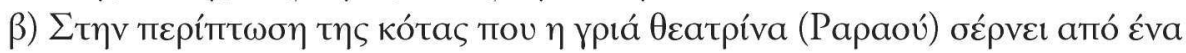

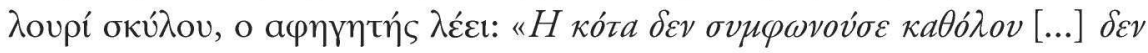

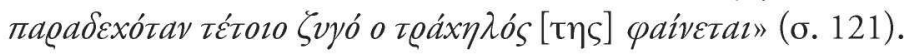

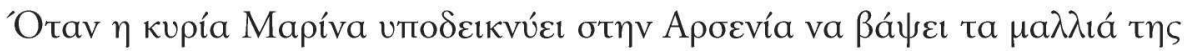

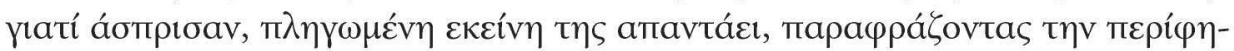

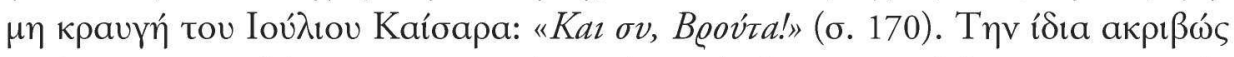

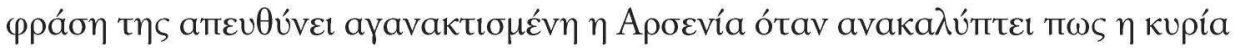

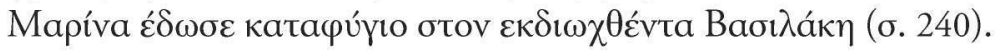

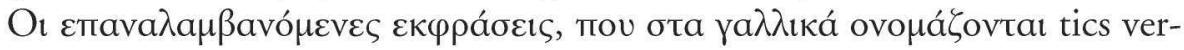

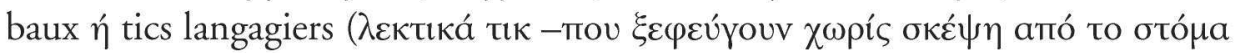

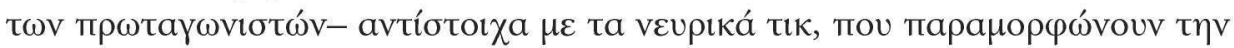

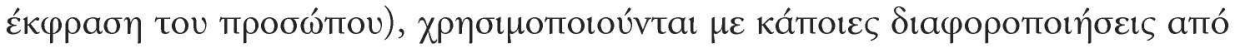

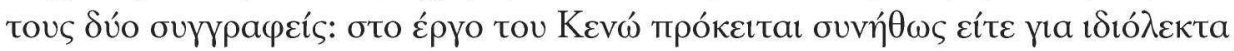

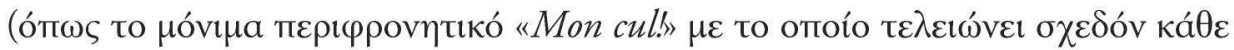

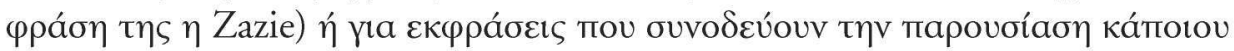

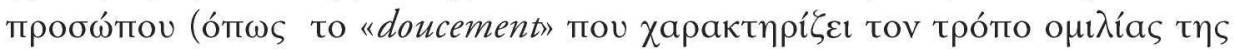

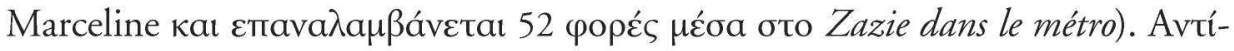

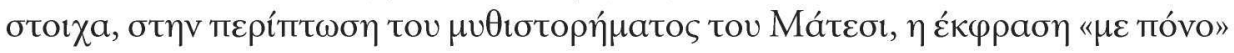

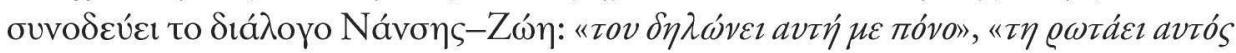

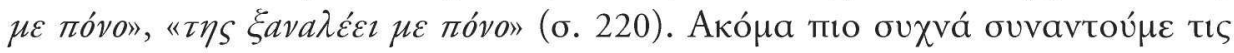

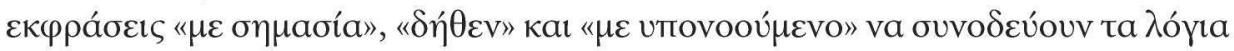

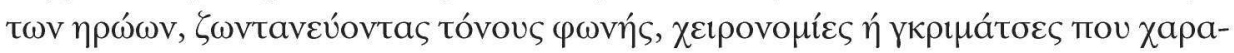

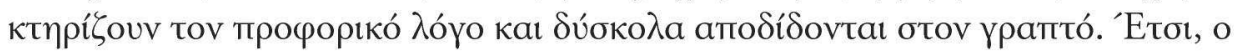

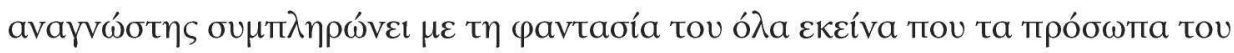

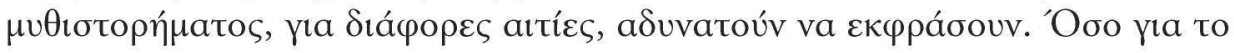




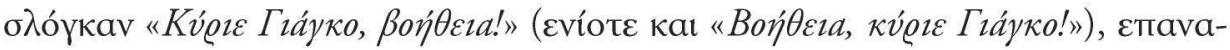

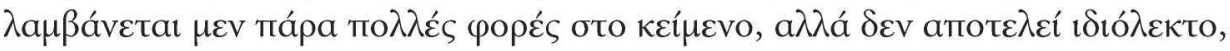

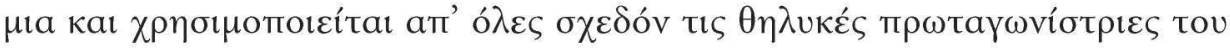

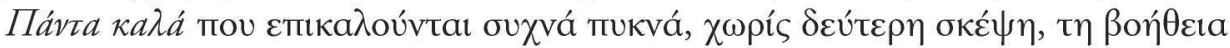

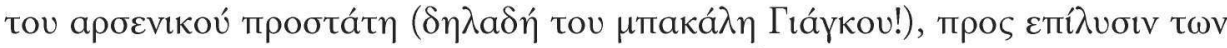

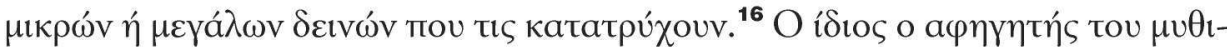
бторй

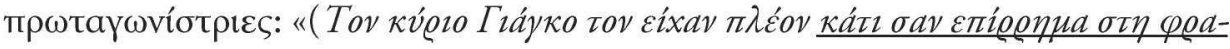

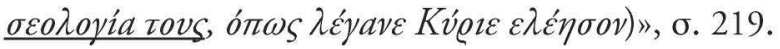

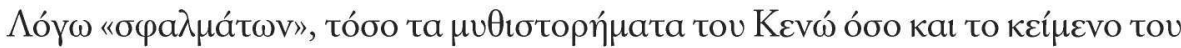

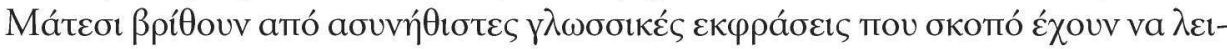

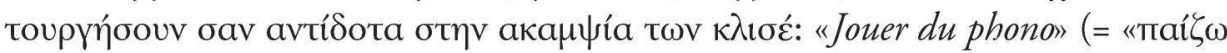

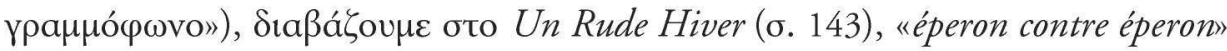

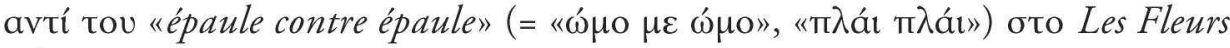

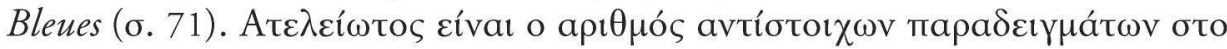

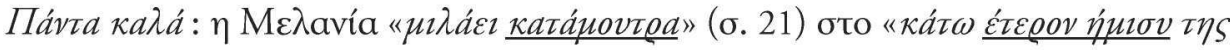

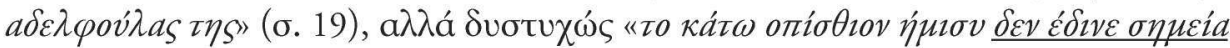

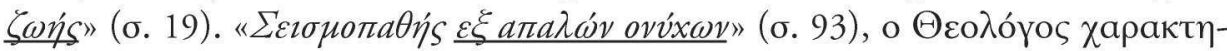

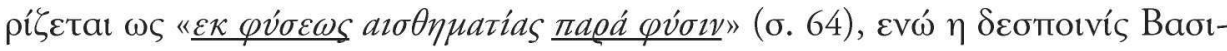

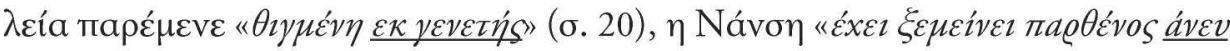

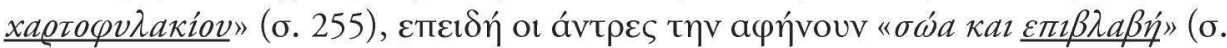

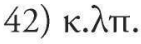

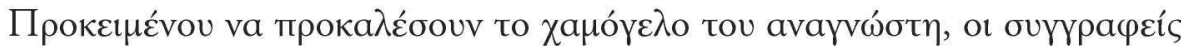

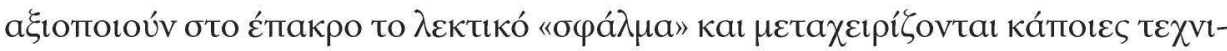

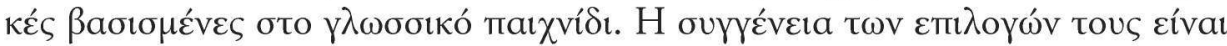

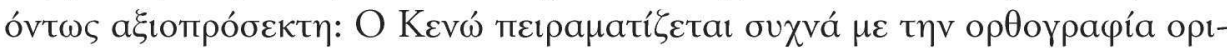

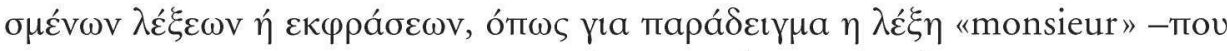
үра́

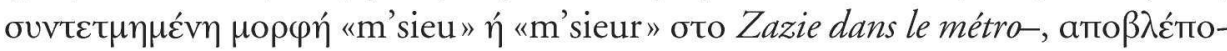

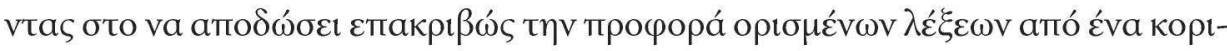

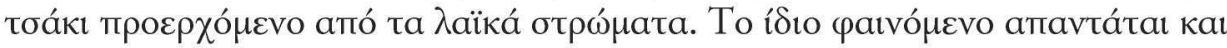

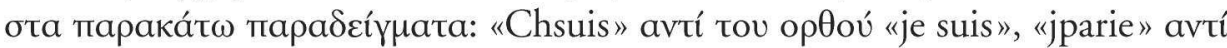

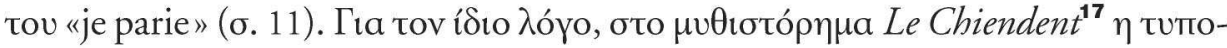

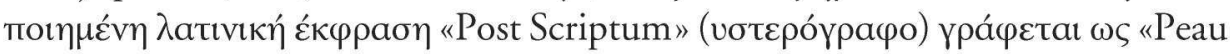

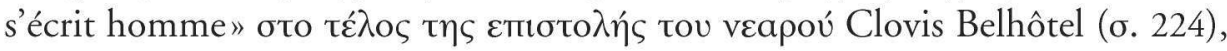

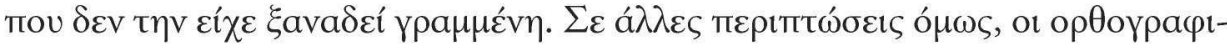

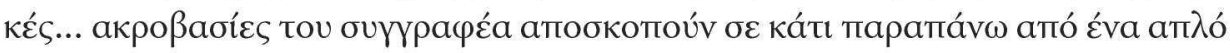




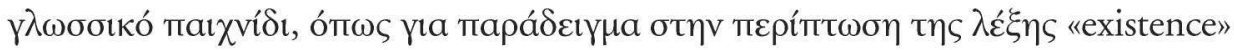

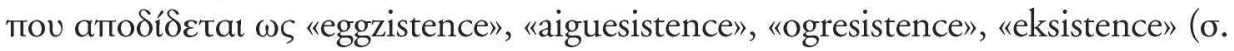

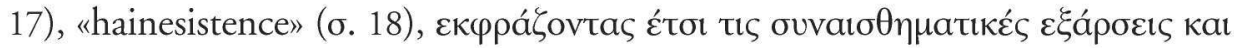

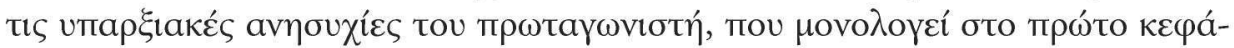

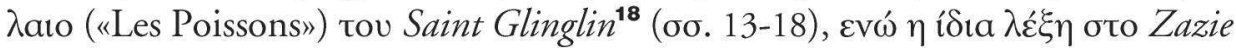

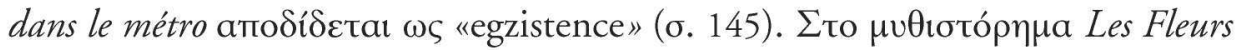

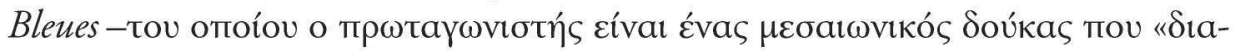

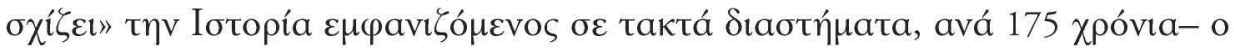

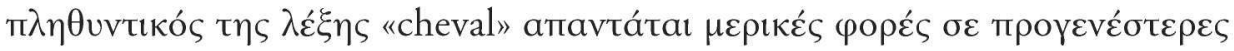

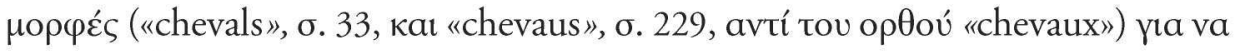

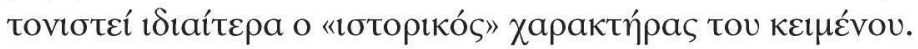

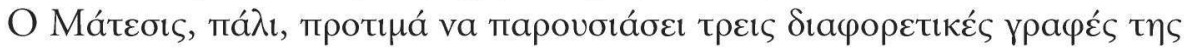

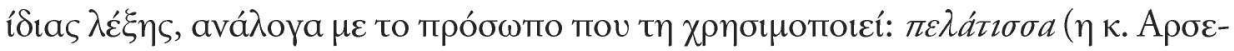

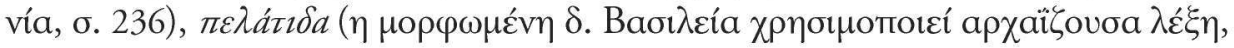

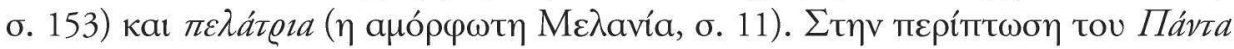

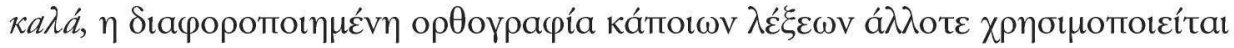

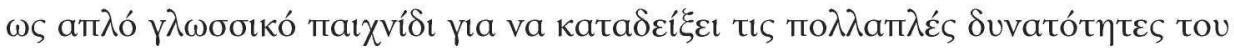

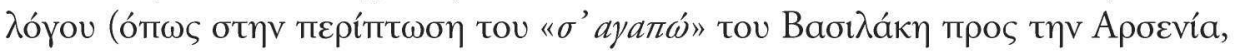

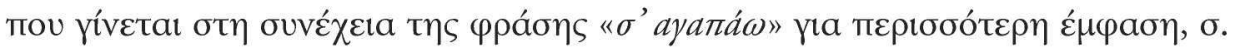
128) ท́ т

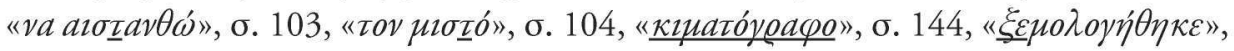

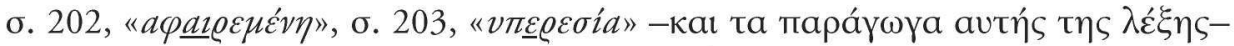

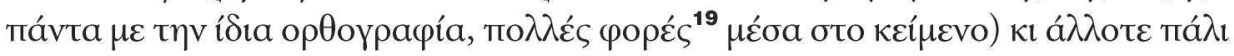

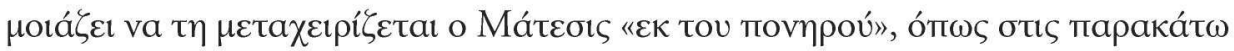

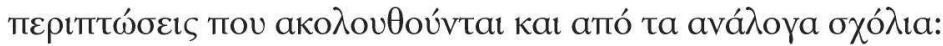

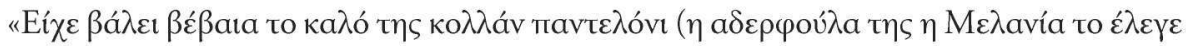

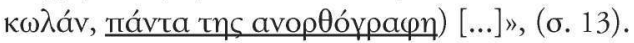

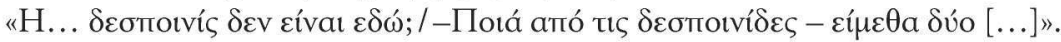

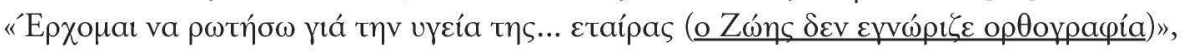
(б. 66).

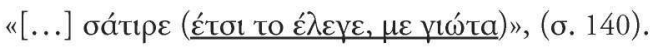

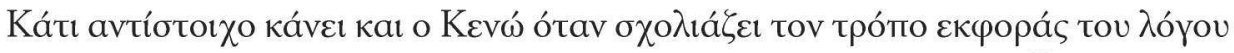

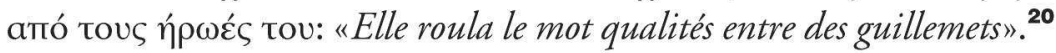

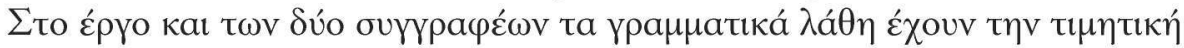

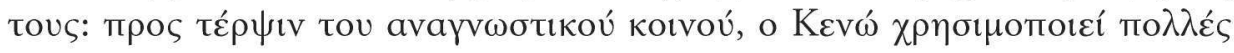

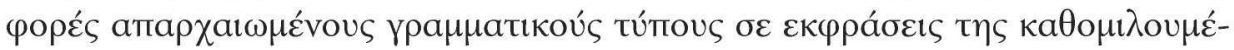

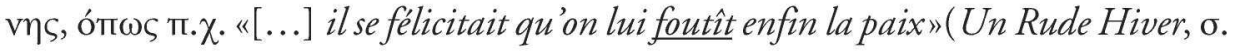




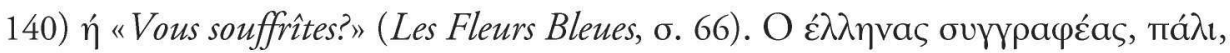

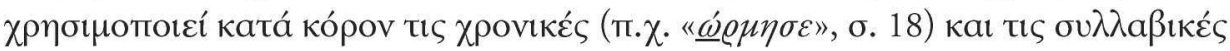

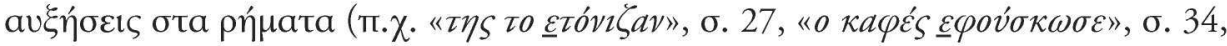

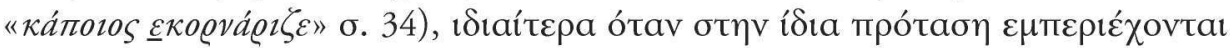

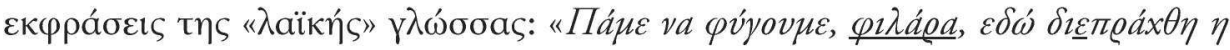

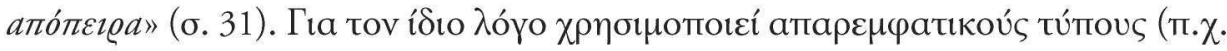

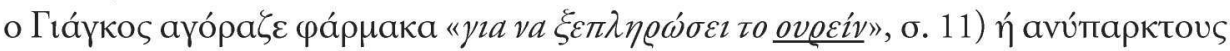

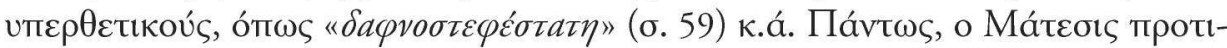

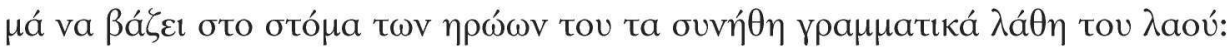

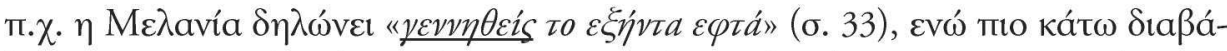

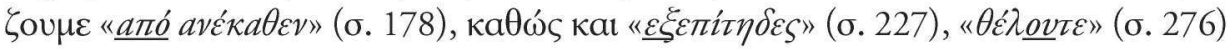

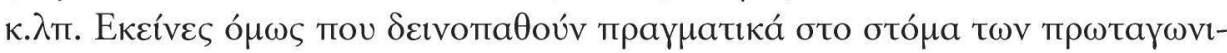

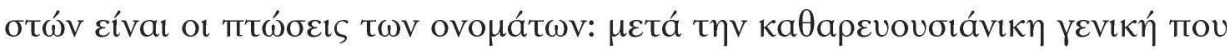

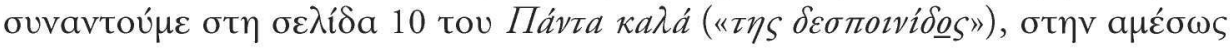

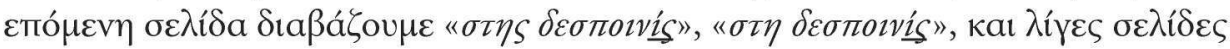

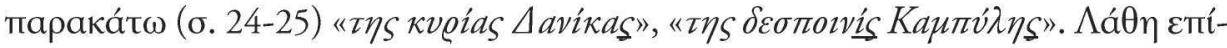

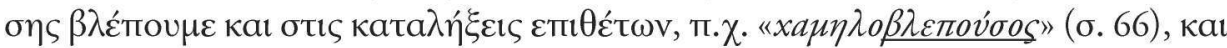

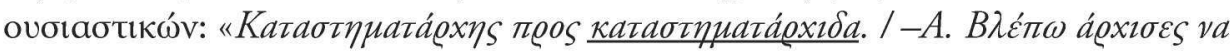

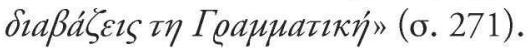

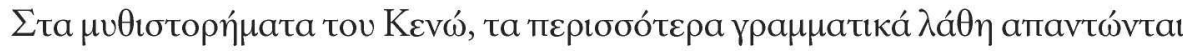

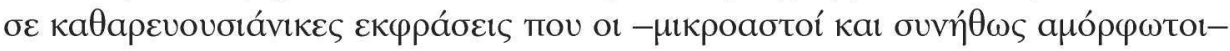

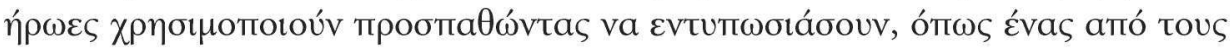

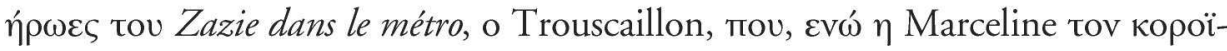

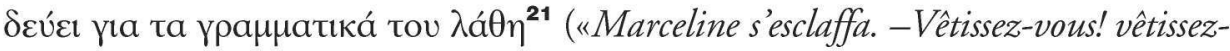

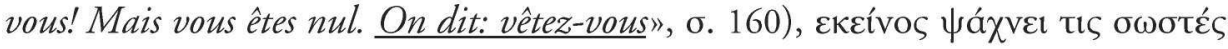

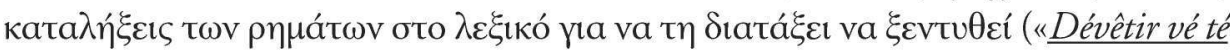

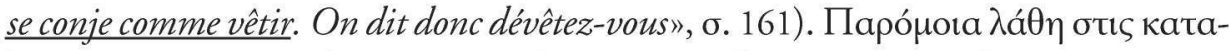

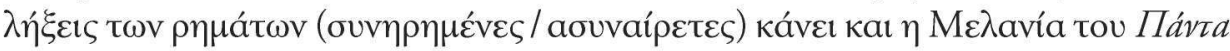

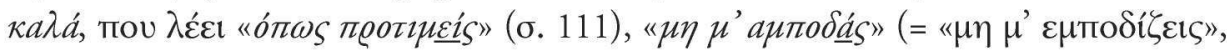

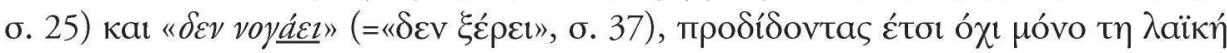

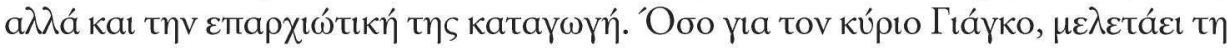

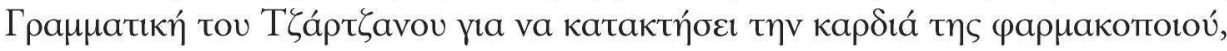

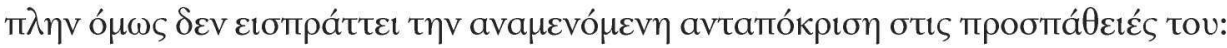

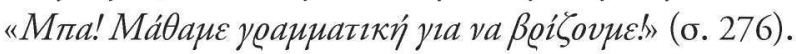

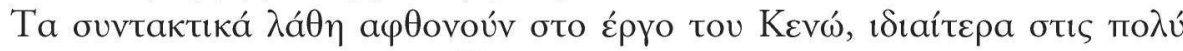

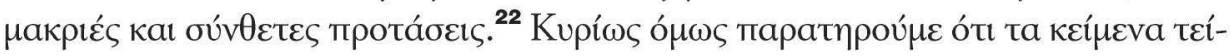

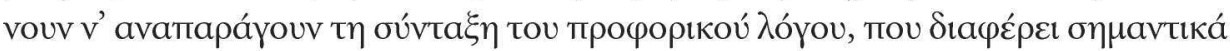




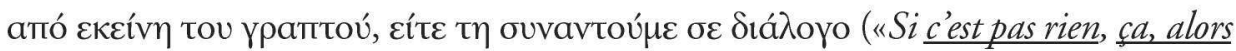

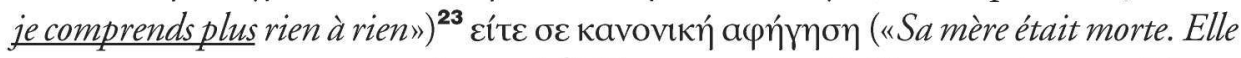

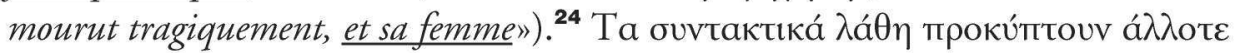

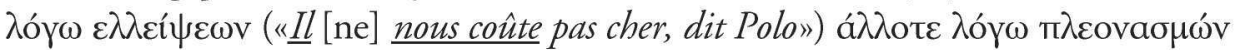

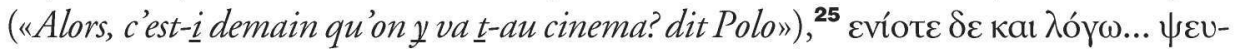

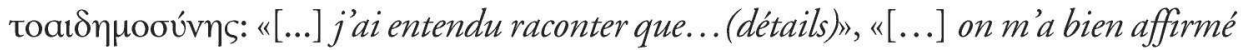

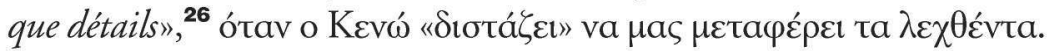

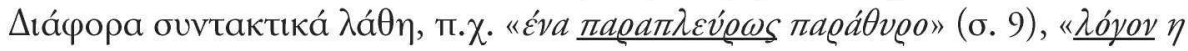

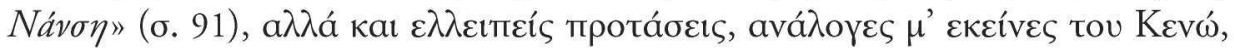

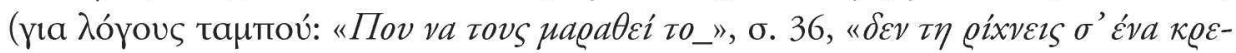

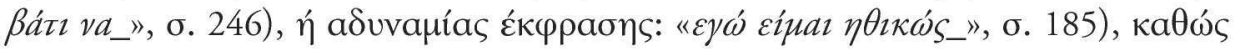

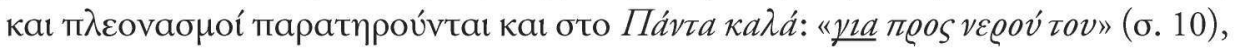

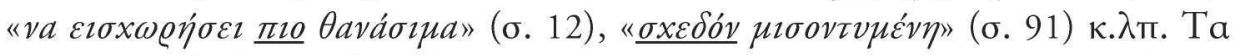

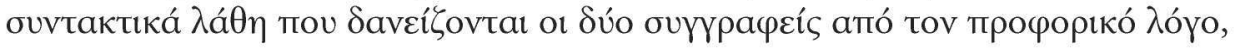

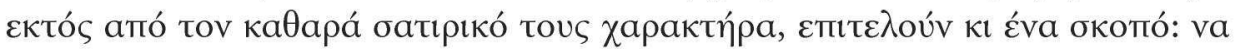

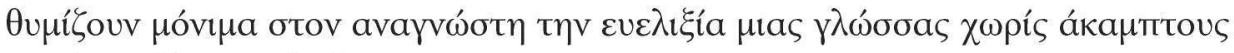

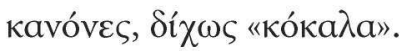

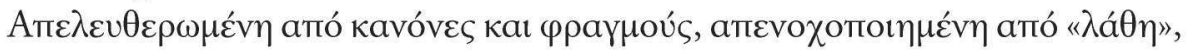
$\eta$ ү

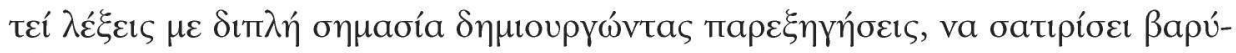

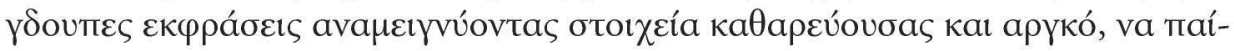

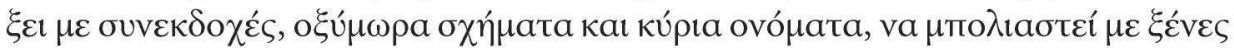

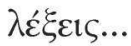

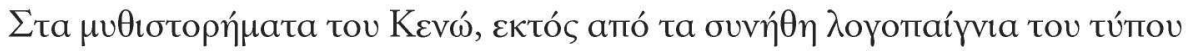

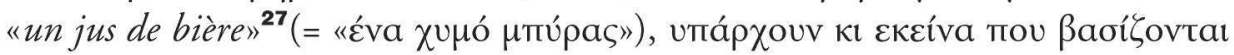

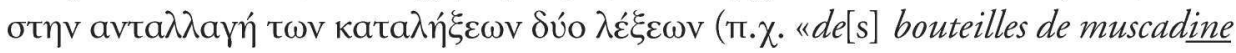
et de grenadets", ${ }^{\mathbf{2 8}}$ "silentaire et solicieux», ${ }^{\mathbf{2 9}}$ "de[s] jambes apolliniaques ou plutôt

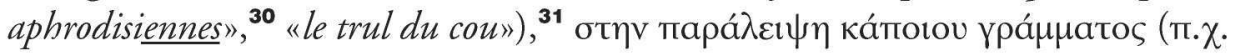

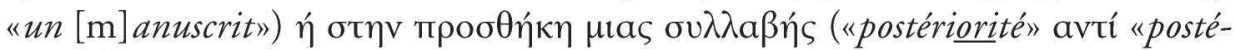

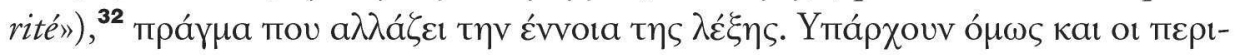

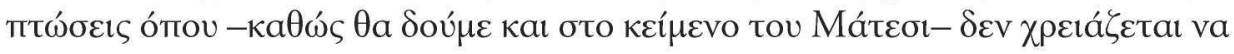

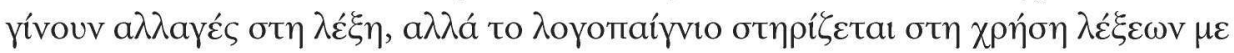

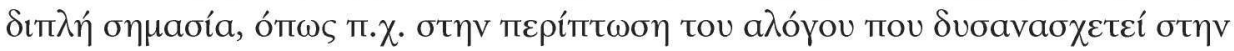

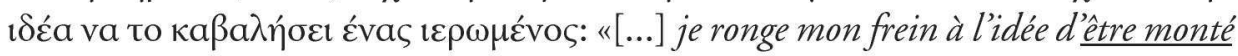
par un ecclésiastique». ${ }^{33}$

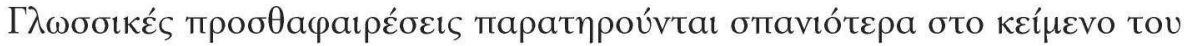

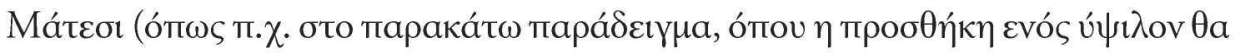




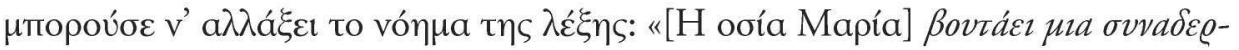

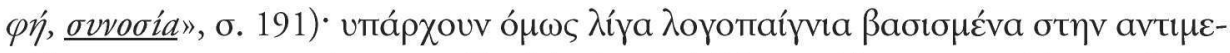

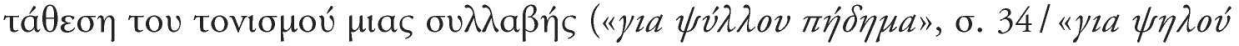

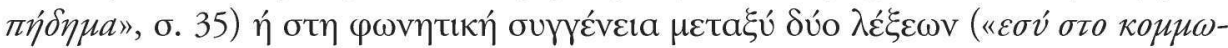

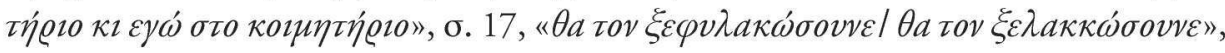

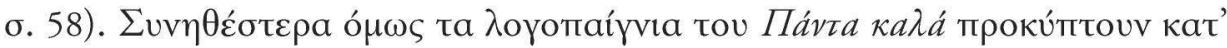

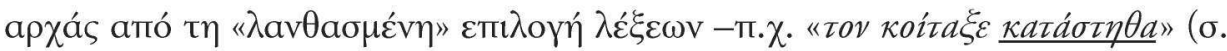

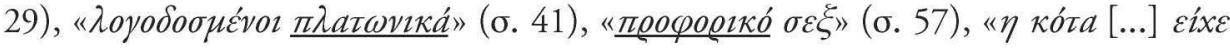

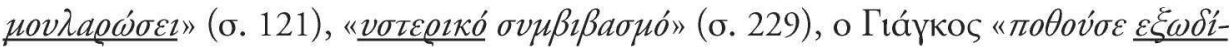

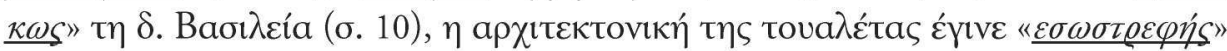

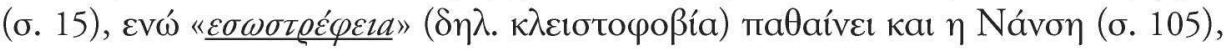

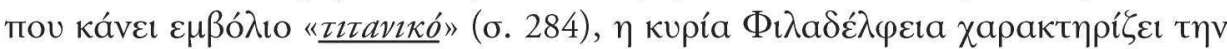

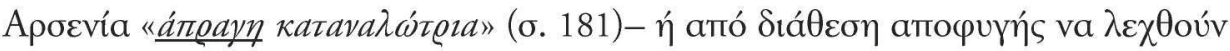

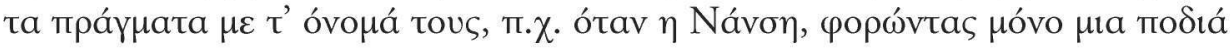

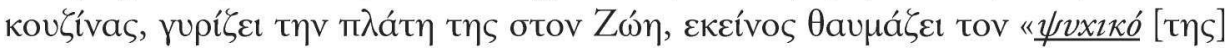

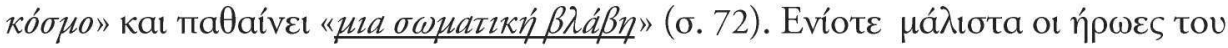

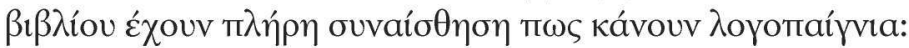

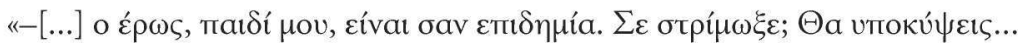

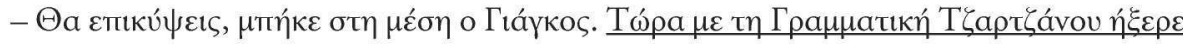

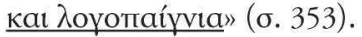

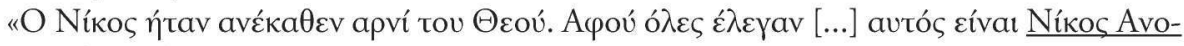
ұńs" (б. 363).

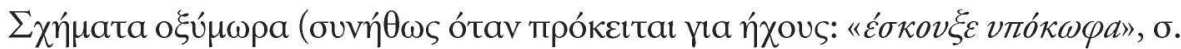

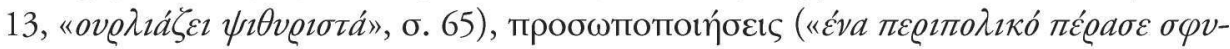

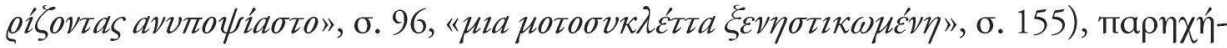

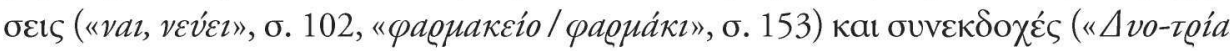

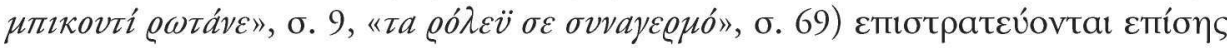

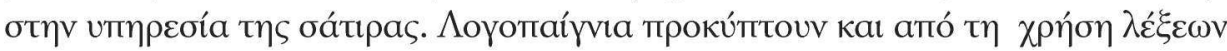

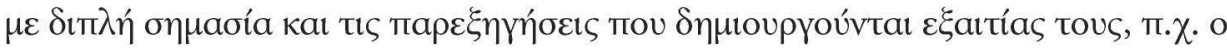

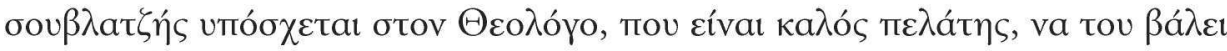

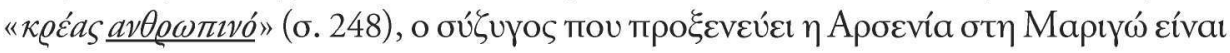

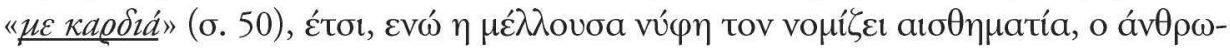

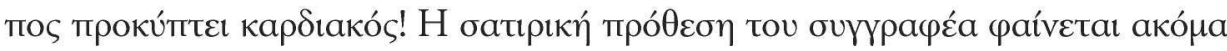

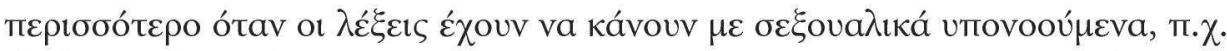

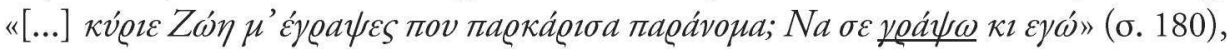

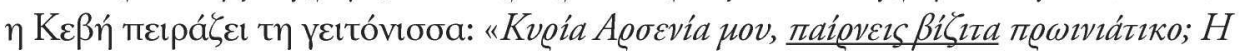

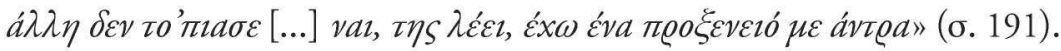




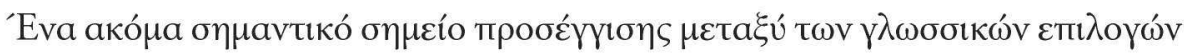

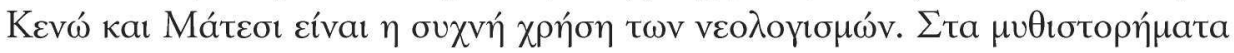

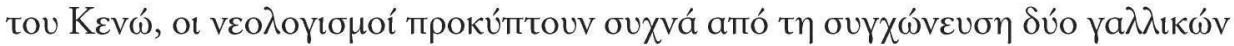
$\lambda \varepsilon \dot{\xi} \xi \varepsilon \mathrm{\varepsilon}$ : «franciscopolitaine», (aтó to France + métropolitaine, Un Rude Hiver, б. 20), «cochoncetés» (cochonneries + méchancetés, Zazie dans le métro, o. 21), $\eta$

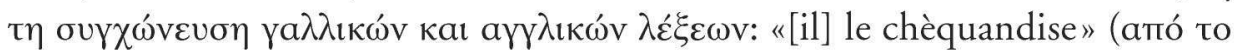

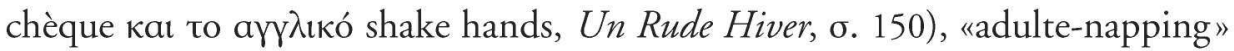

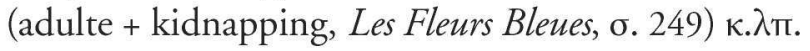

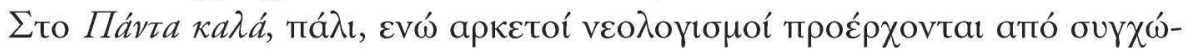

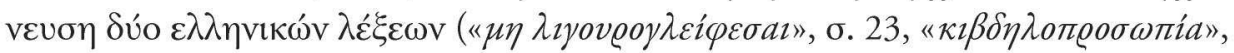

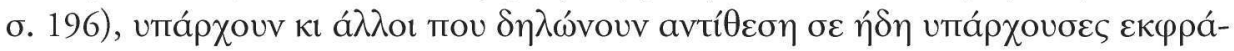

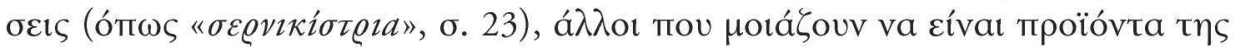

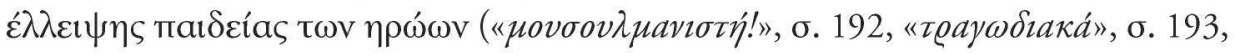

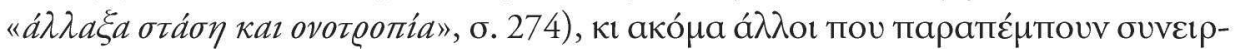

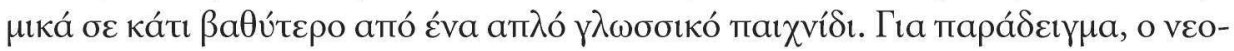

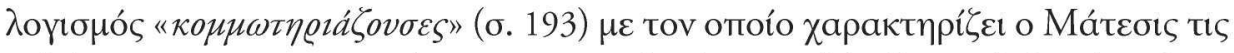

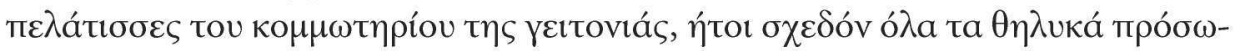

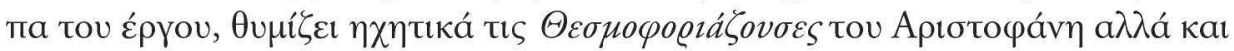

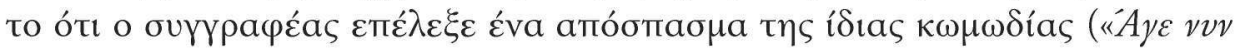

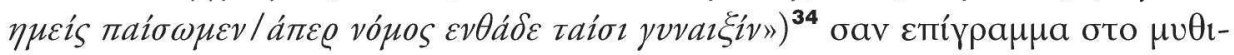

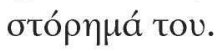

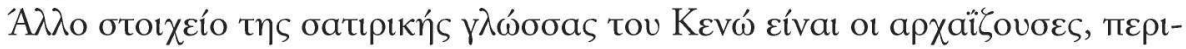

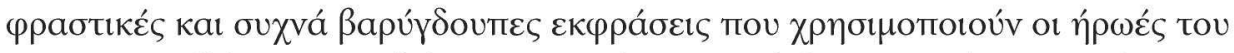

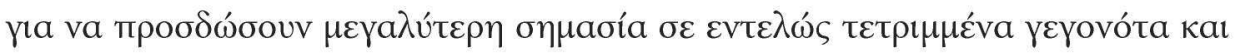

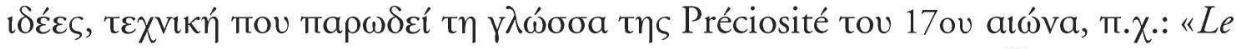
rouge de la honte vint teinter la blanche carnation de la grasse Lalie» " ("то ко́ккเvо

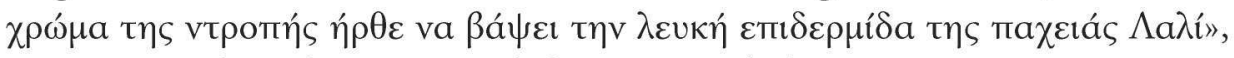

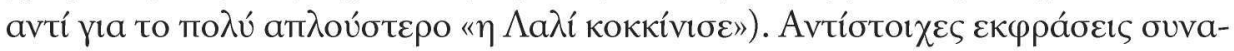

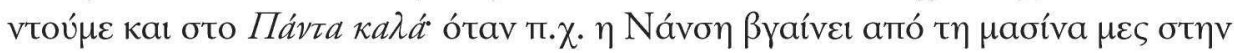
отоі́a

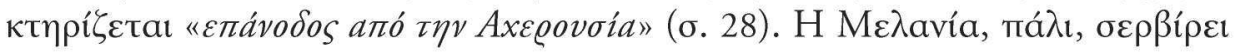

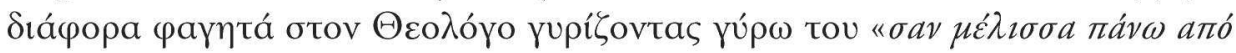

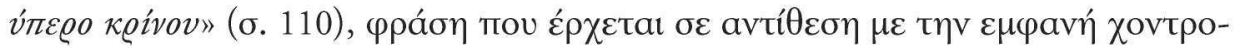

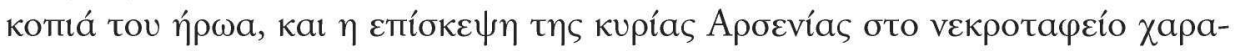

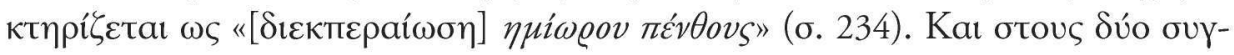

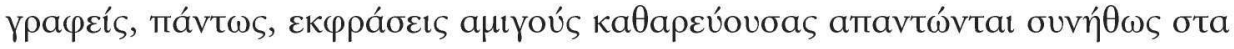

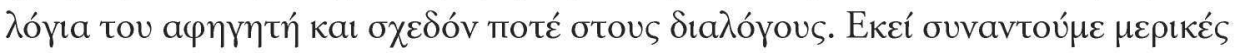




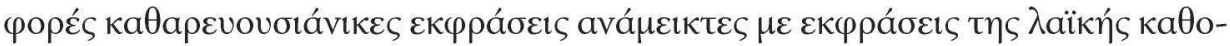

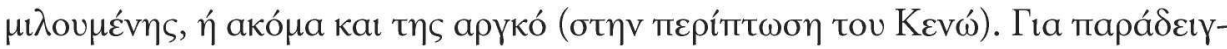

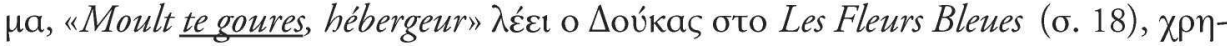

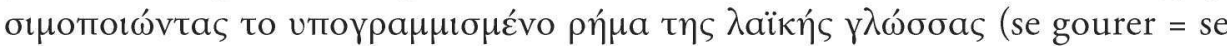

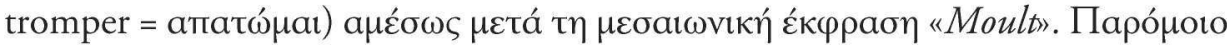
ү

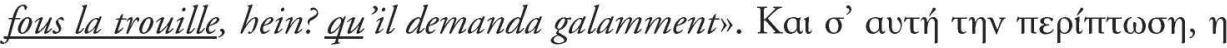

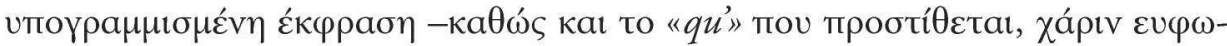

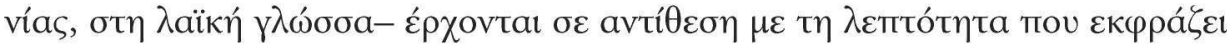

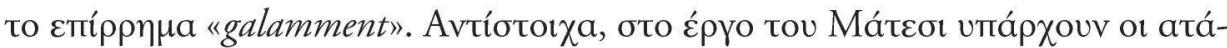

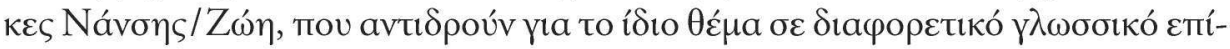

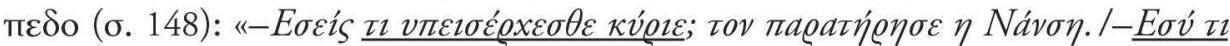

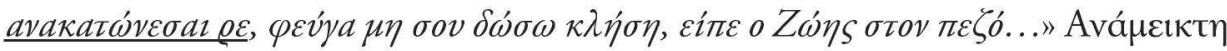

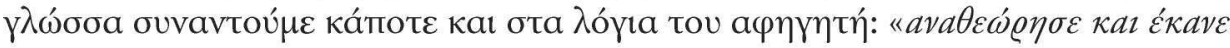

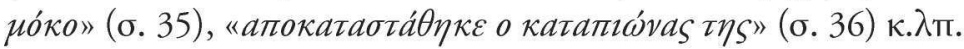

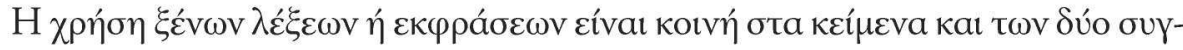

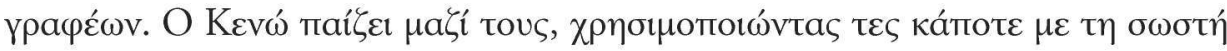

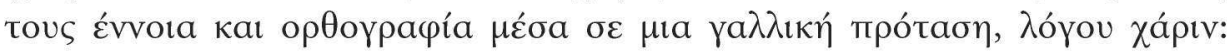
«Natürlich, dit Jeanne [...]», «Allons grouillons! Schnell! Schnell!» (Zazie dans le

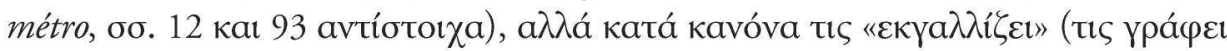

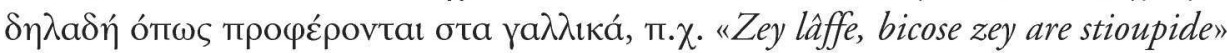

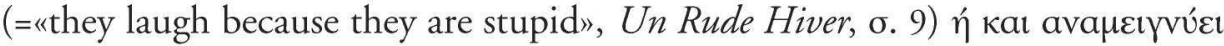

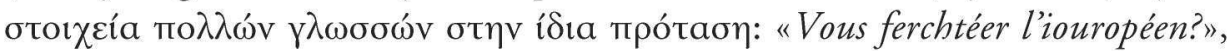

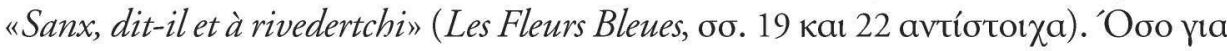

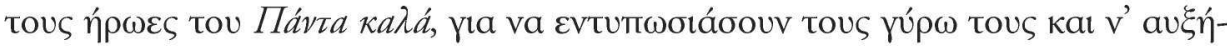

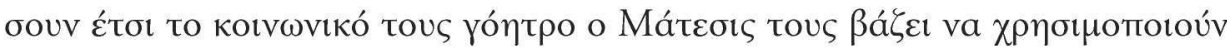

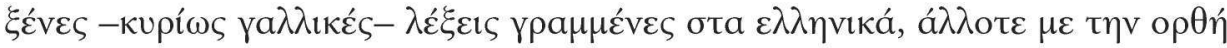

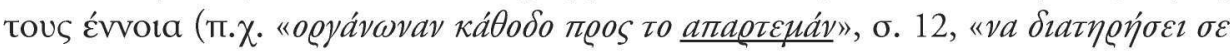

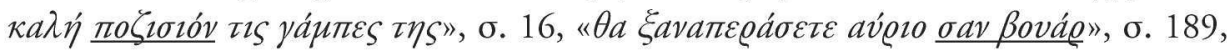

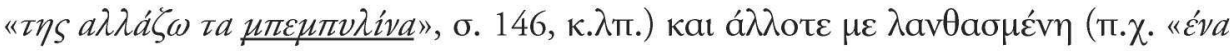

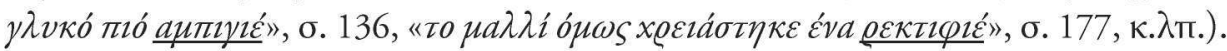

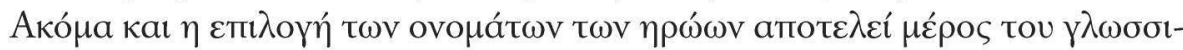

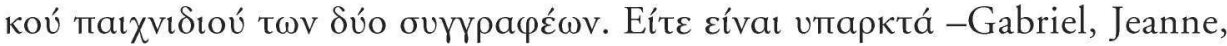
Charles oto Zazie dans le métro, Bernard, Annette, Madeleine oto Un Rude

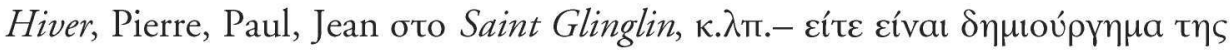

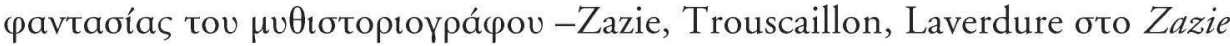
dans le métro, Cidrolin, Lamélie, Mouscaillot oto Les Fleurs Bleues, Sénateur, 


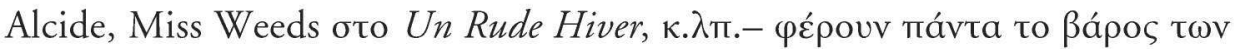

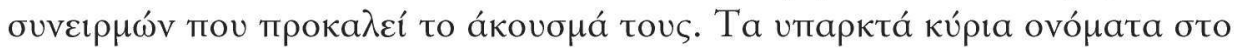

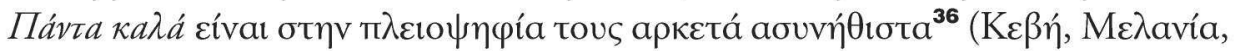

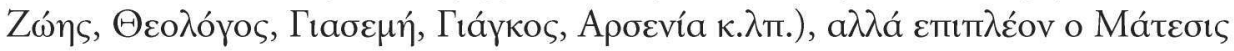

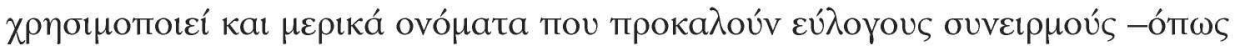

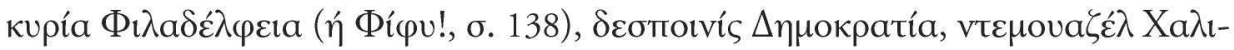

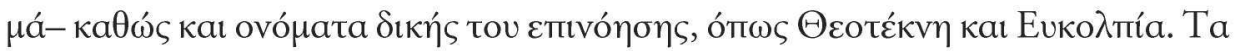

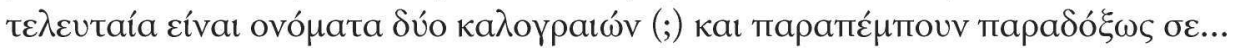

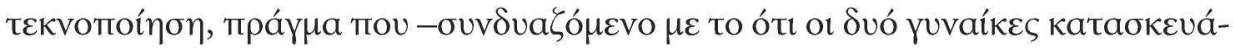

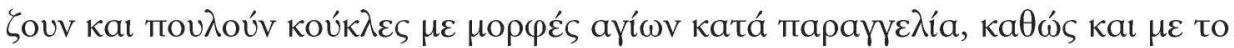

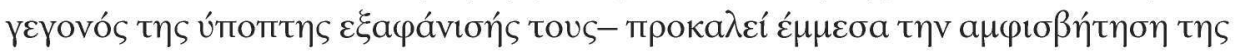

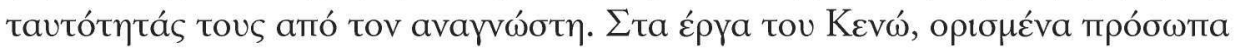

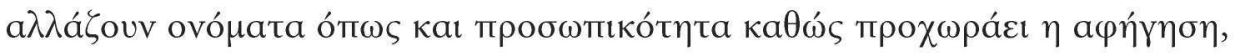

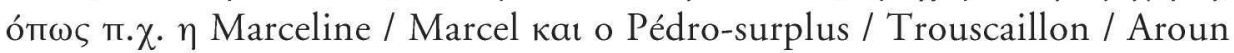

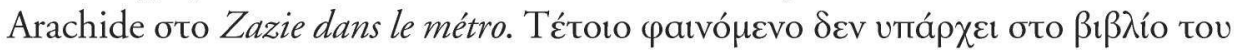

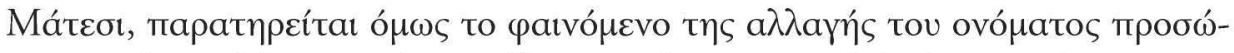

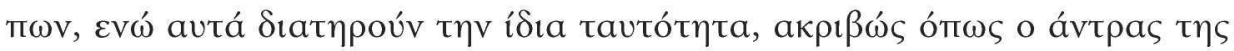

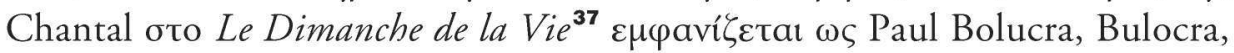

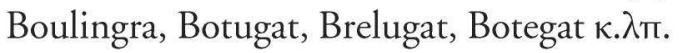

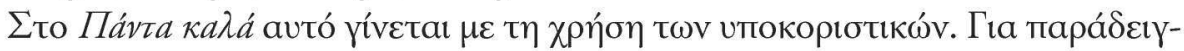

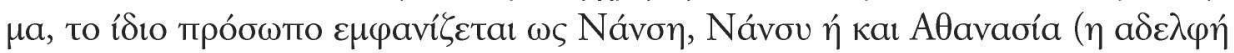

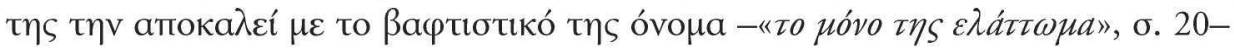

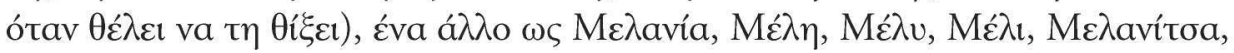

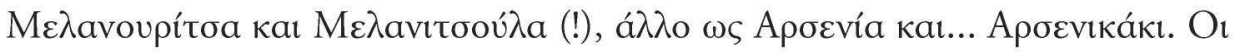

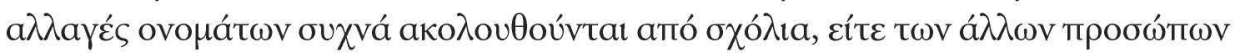

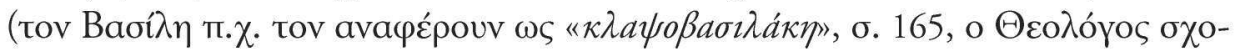

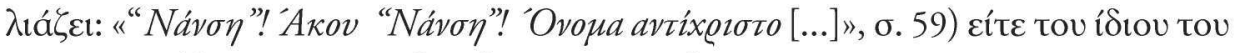

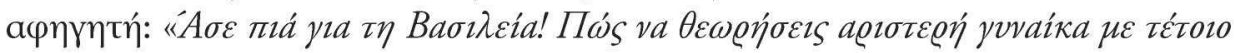

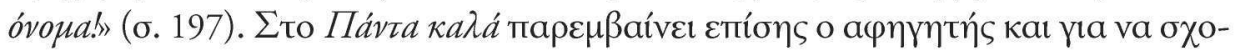

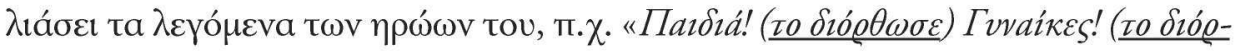
$\underline{\theta \omega \sigma \varepsilon})$ Ko

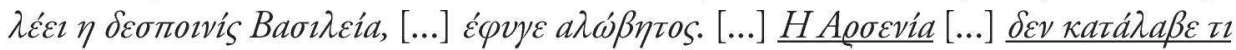

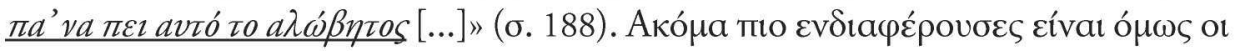

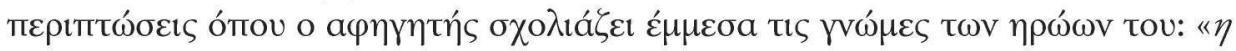

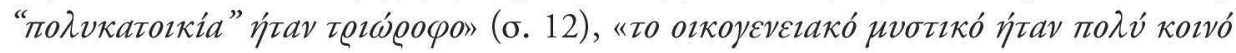

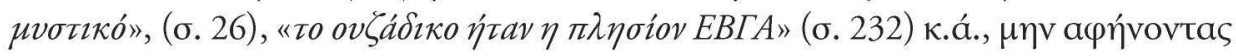

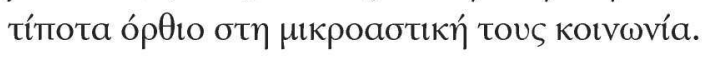




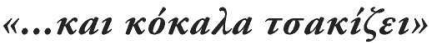

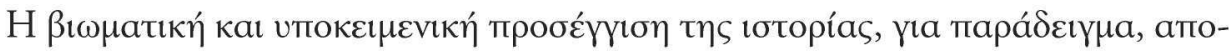

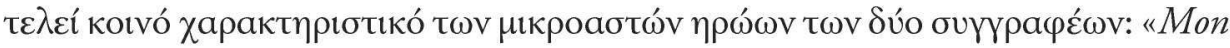
père alla chercher ses gros sous à la Banque / parce qu'un Serbe avait tué là-bas

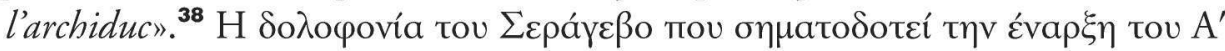

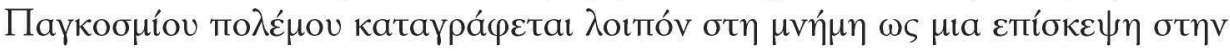

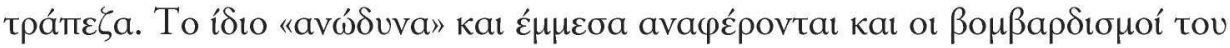

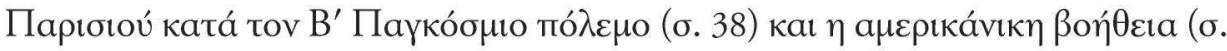

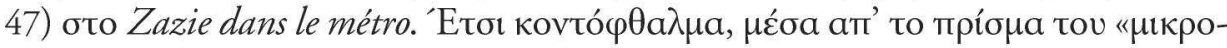

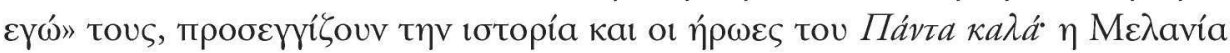

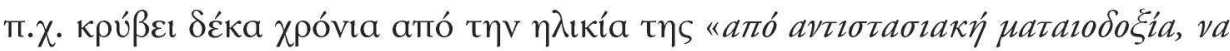

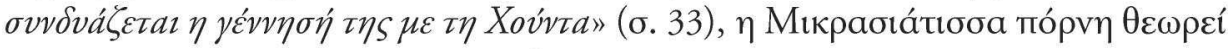

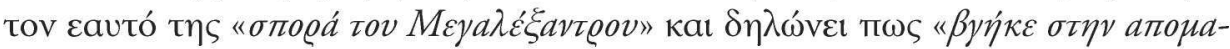

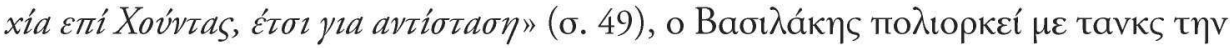

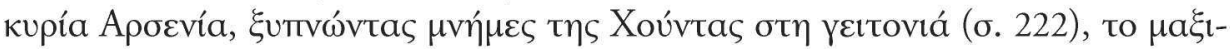

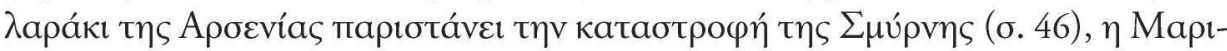

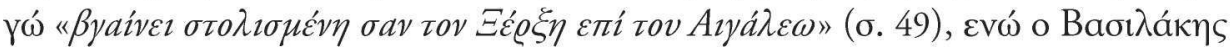

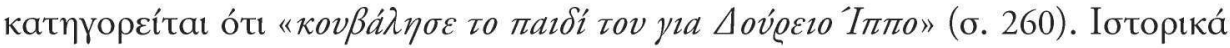

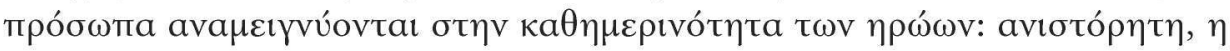

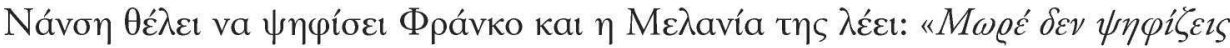

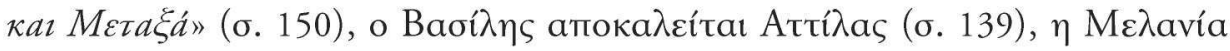

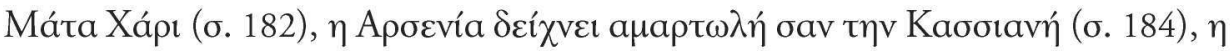

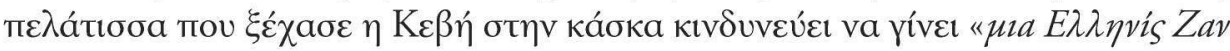

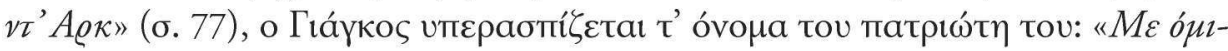

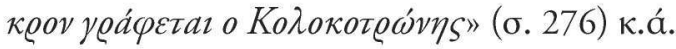

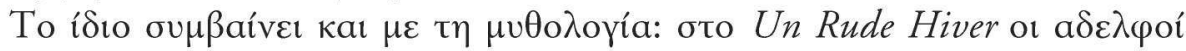

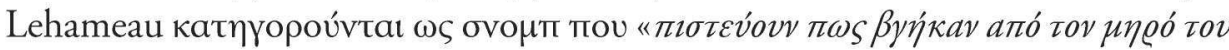

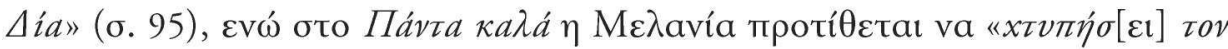

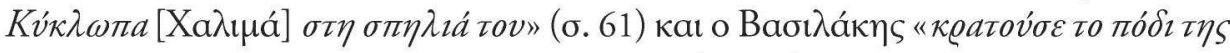

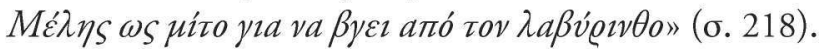

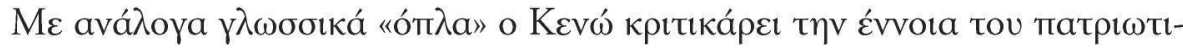

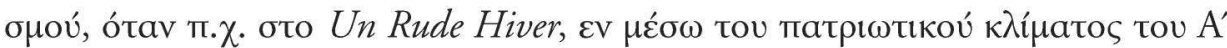

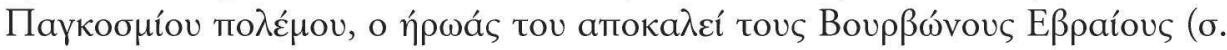

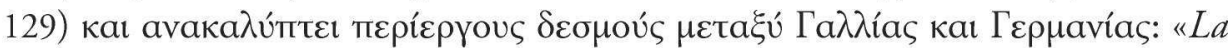
France? C'est le pays des Francs. Qu'est-ce que c'était que les Francs? Des Allemands»

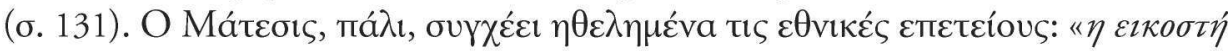




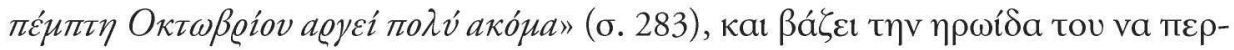

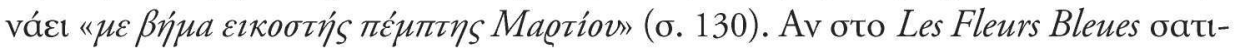

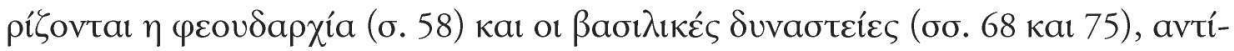

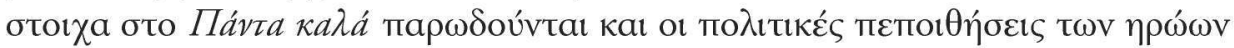

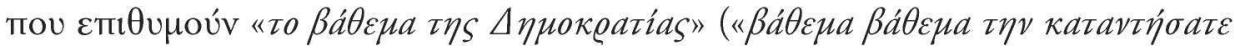

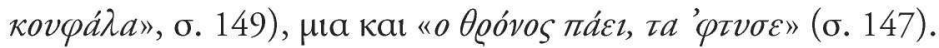

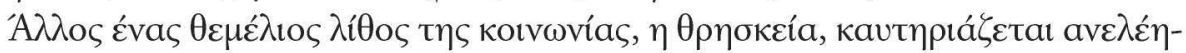

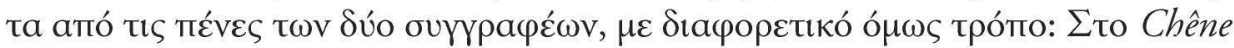

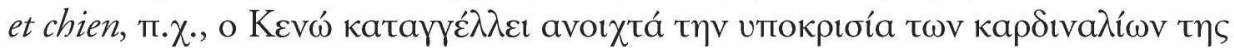

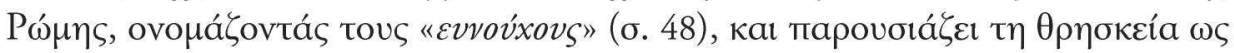

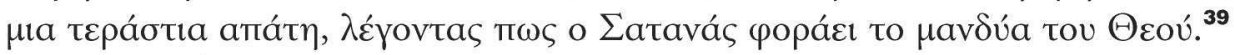

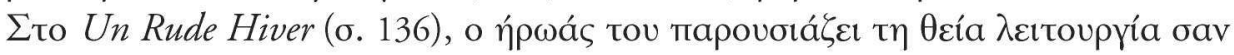

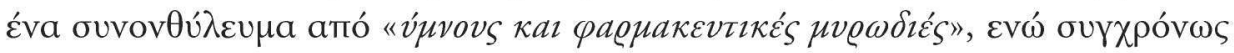

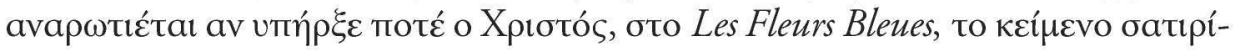

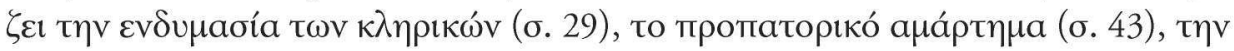

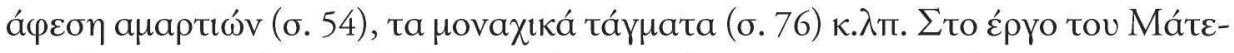

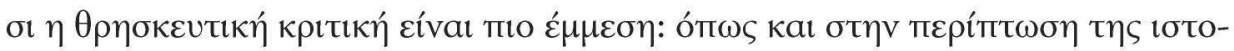

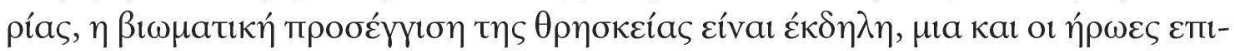

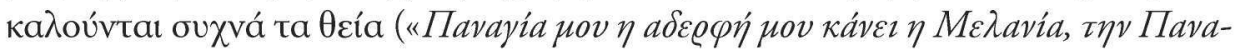

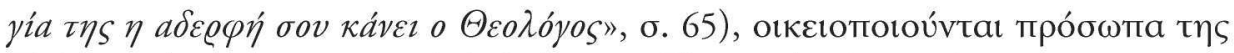

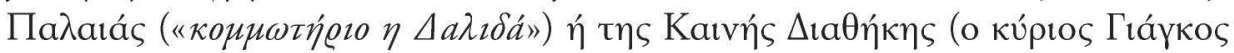

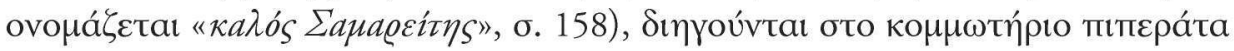

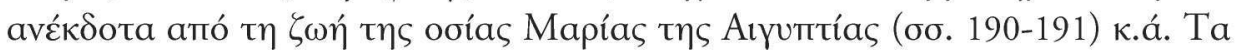

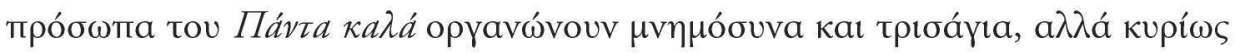

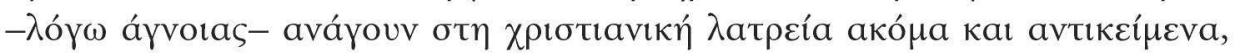

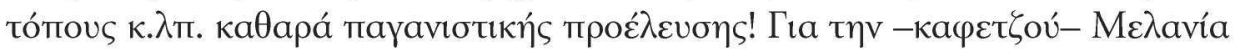

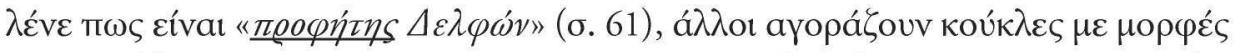

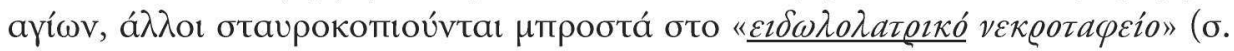

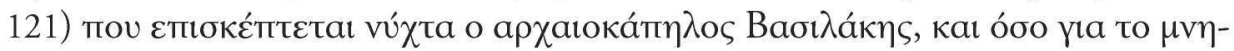

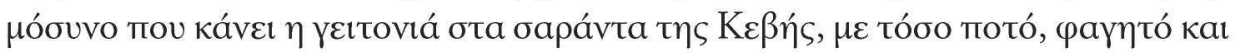

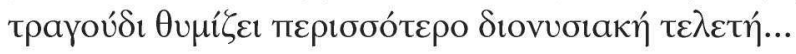

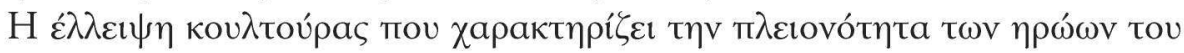

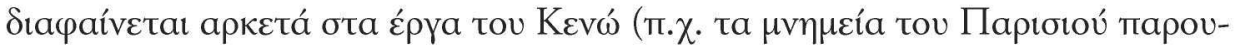

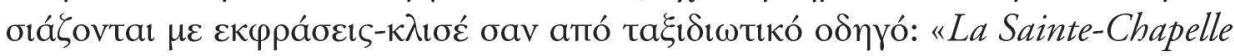

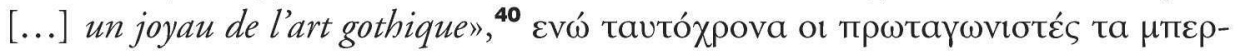

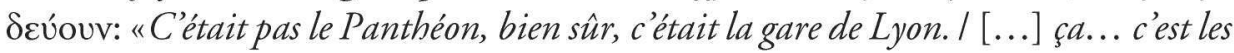
Invalides [...] / ça n'a rien à voir avec les Invalides [...] c'est tout au plus la caserne 


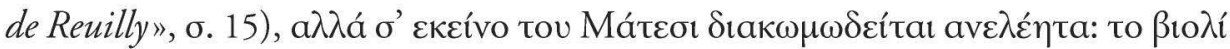

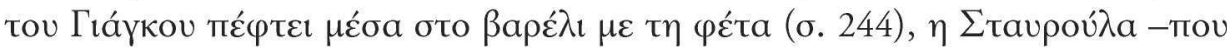

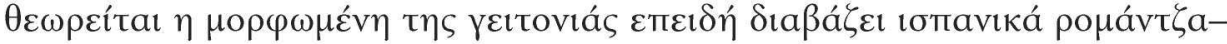

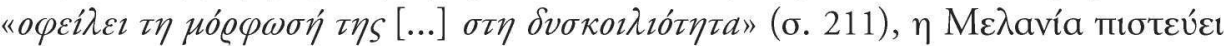

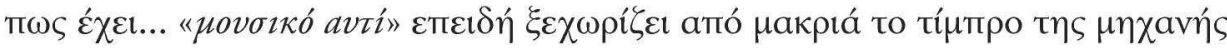

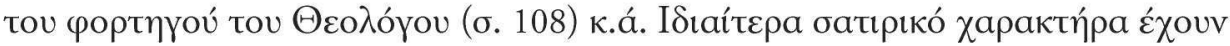

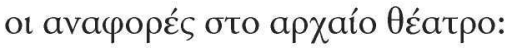

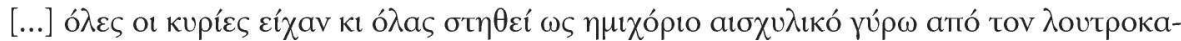

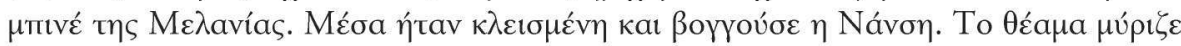

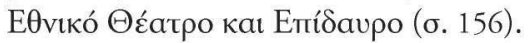

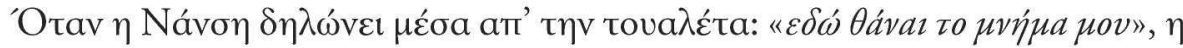

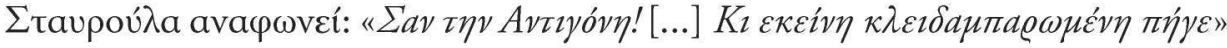

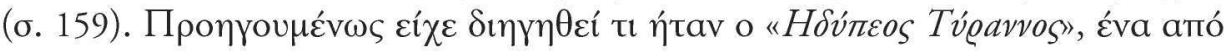

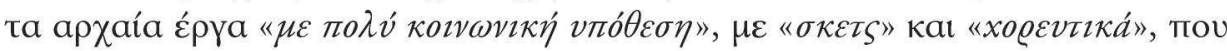

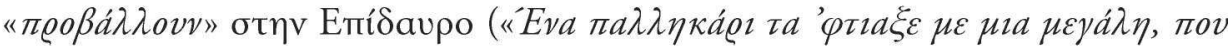

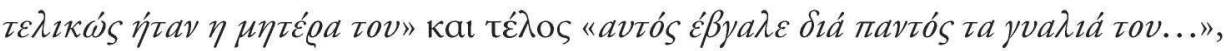
бо. 156-157).

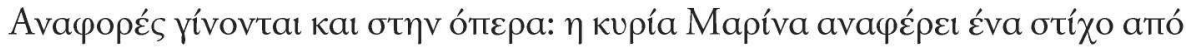

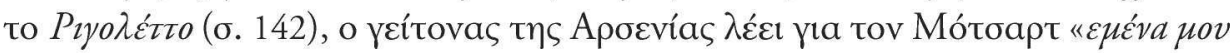

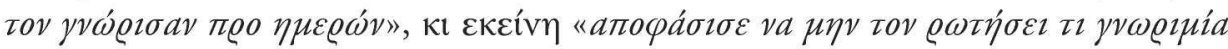

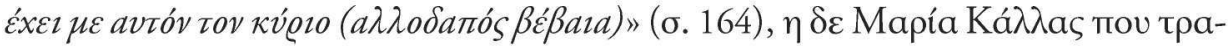

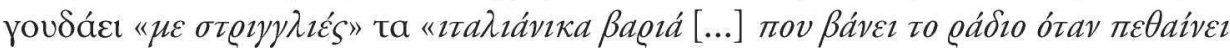

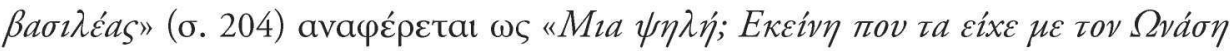

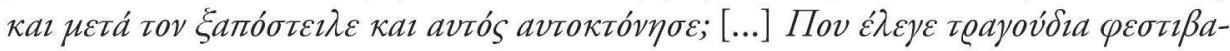

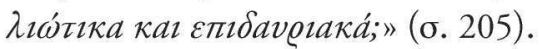

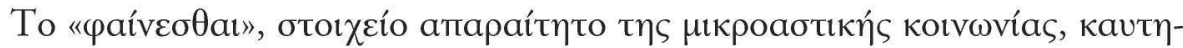

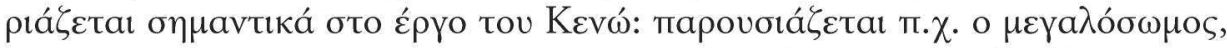

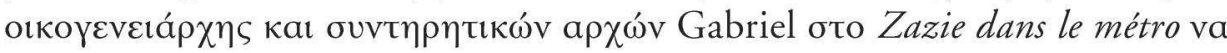

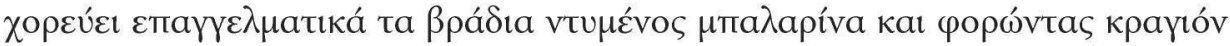

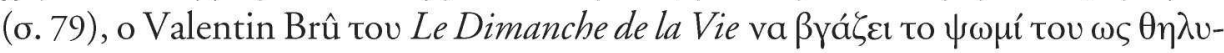

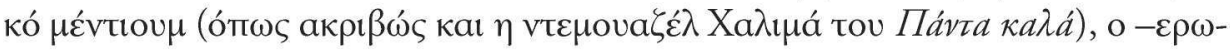

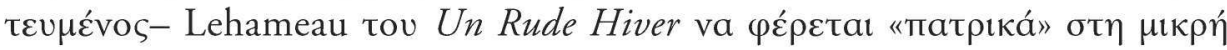

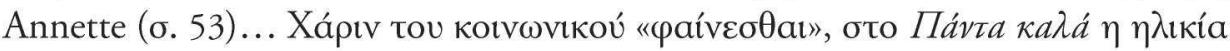

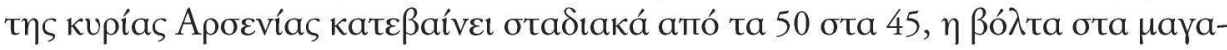

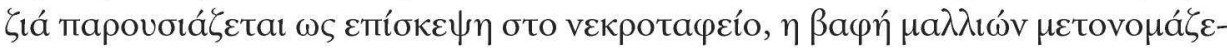

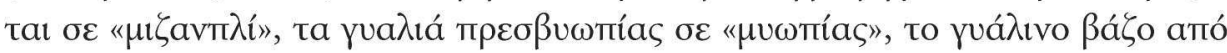




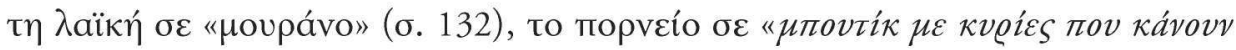

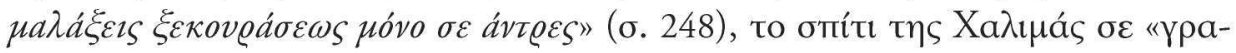

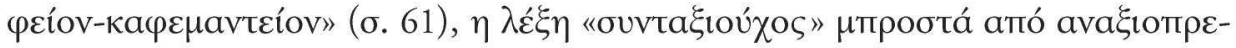

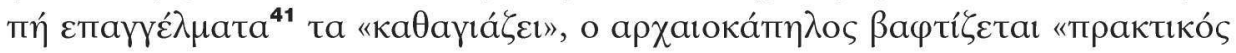

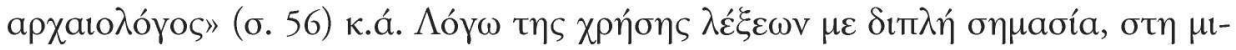

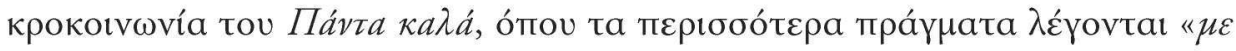

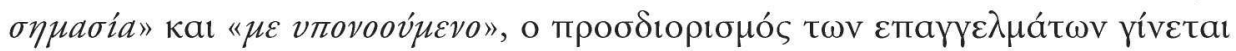

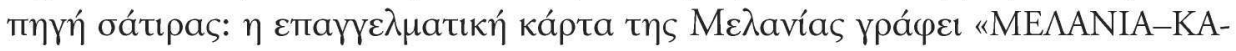

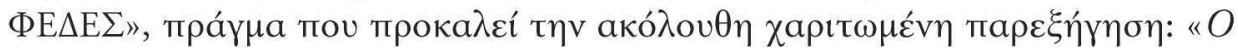

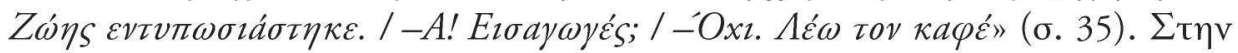

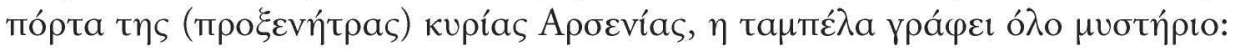

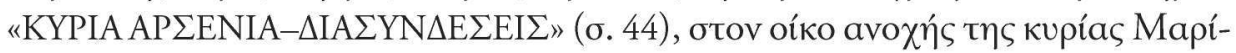

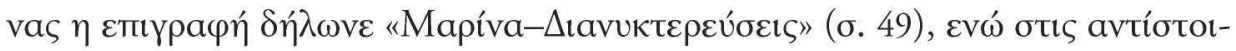

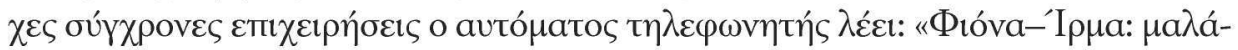

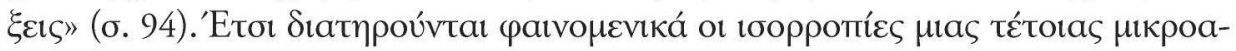

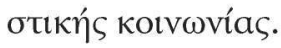

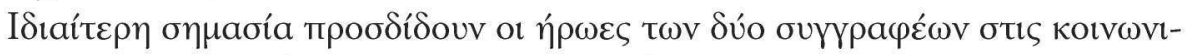

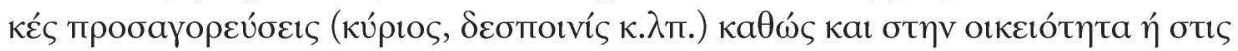

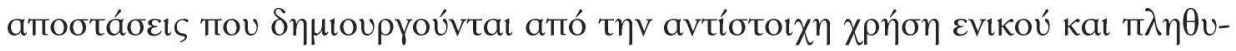
vтเкoú: "Monsieur Lehameau, Bernard, permettez-moi de vous appeler Bernard",

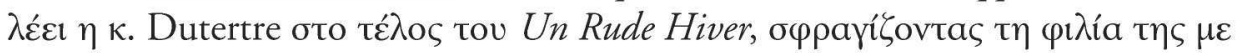

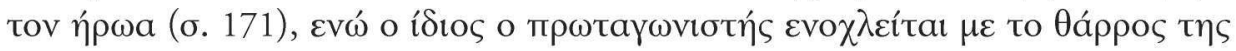

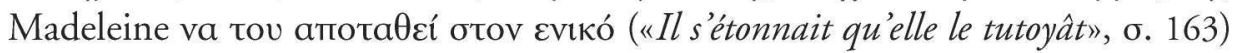

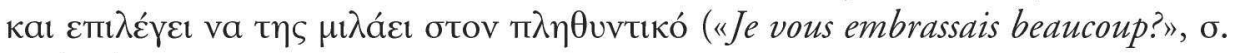

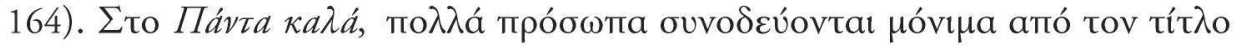

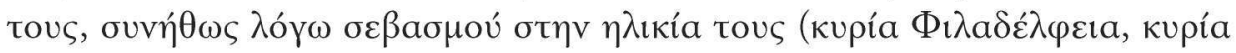

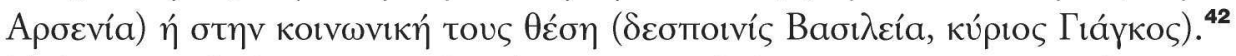

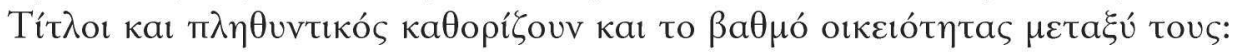

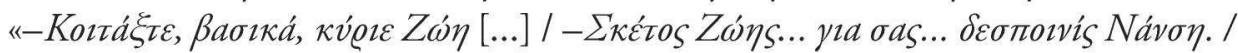

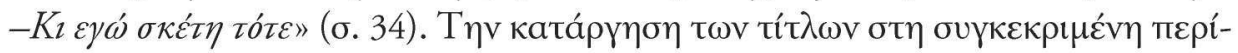

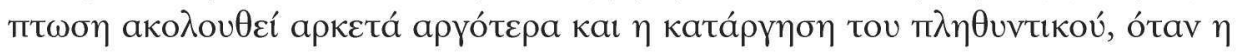

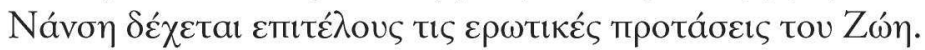

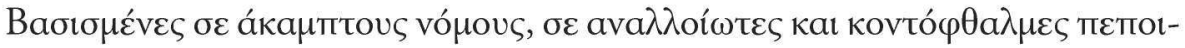

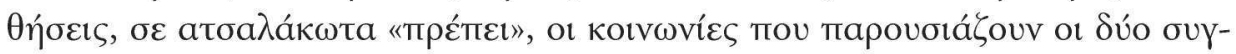

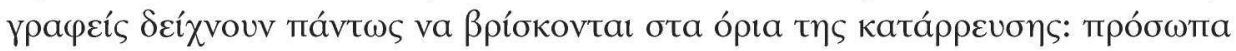

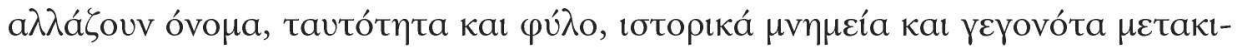

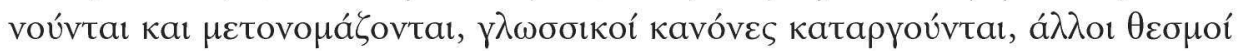




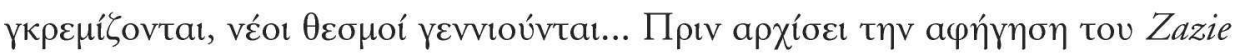

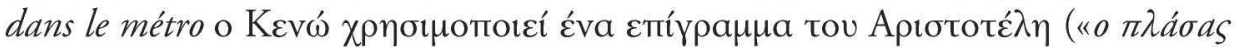

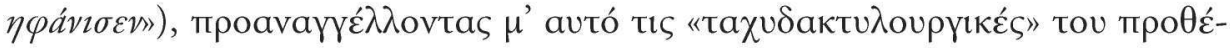

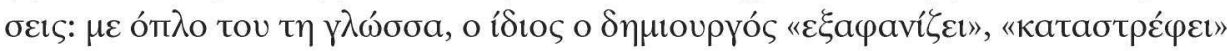

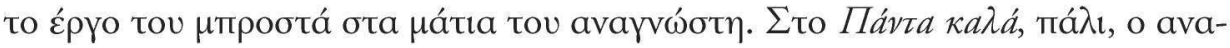

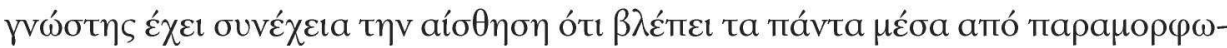

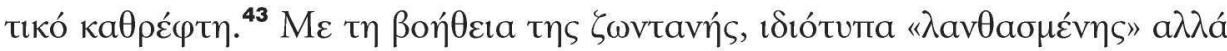

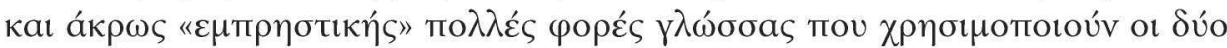
бuүүрарєі́

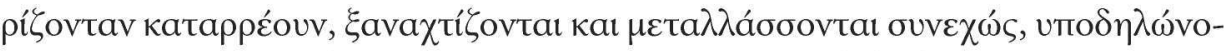

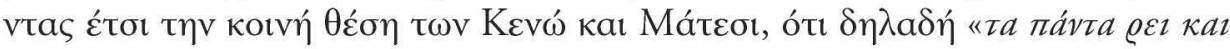

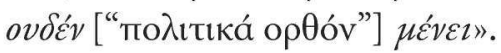

\section{$\Sigma H M E I \Omega \Sigma E I \Sigma$}

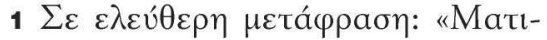

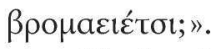

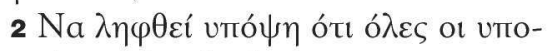

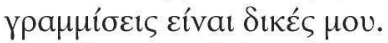

3 Raymond Queneau, Oeuvres comp-

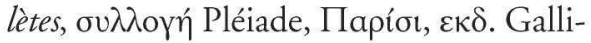
mard, 1989. Апо́бтабна ато́ то боvе́то

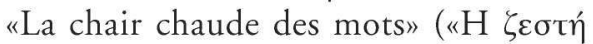

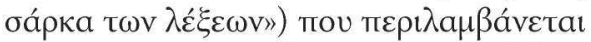

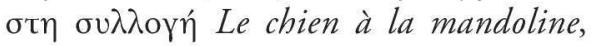

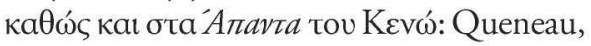
Quvres complètes, o. 317. $\Sigma \varepsilon \varepsilon \lambda \varepsilon v \dot{\theta} \varepsilon \rho \eta$

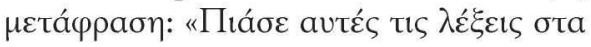

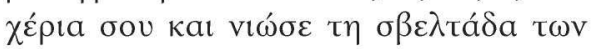

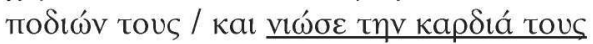

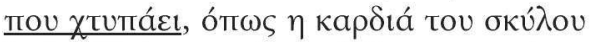

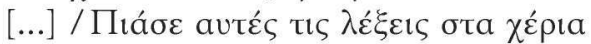

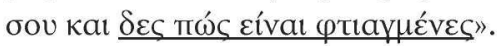

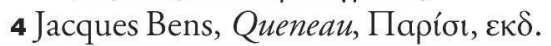

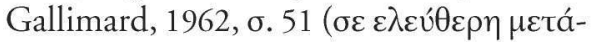

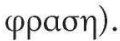

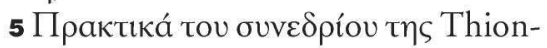
ville $\mu \varepsilon \theta \dot{\varepsilon} \mu \mathrm{a}$ «Raymond Queneau et les

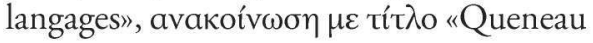

et la linguistique», $\varepsilon \kappa \delta$. Temps mêlés, No

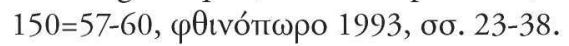

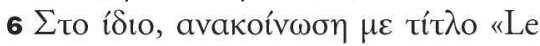
langage de l'humour quenien», бo. 125-134.

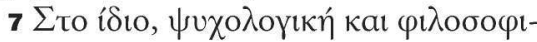

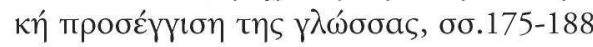

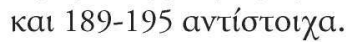

8 Raymond Queneau, Bâtons, chiffres

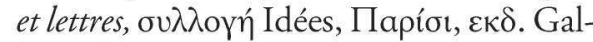

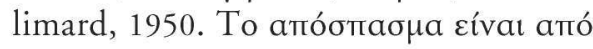

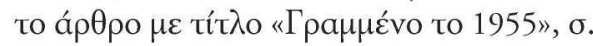

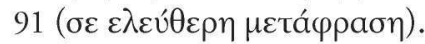

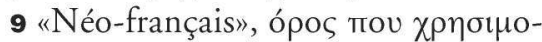

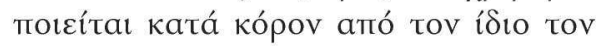

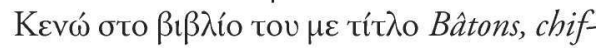
fres et lettres (ó. $\pi$.).

10 Raymond Queneau, Un Rude

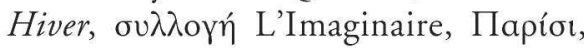
$\varepsilon \kappa \delta$. Gallimard, 1939 каı 1966, б. 107.

11 ¿to íoı, "Il a gagné ses sous à la sueur de son front», $\sigma .96$.

12 Raymond Queneau, Zazie dans le

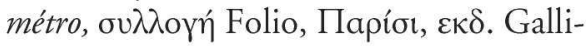
mard, 1959, o. 110. 
13 Raymond Queneau, Les Fleurs Bleues,

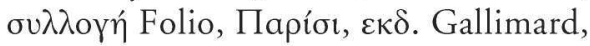

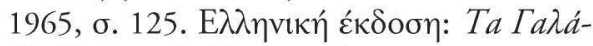

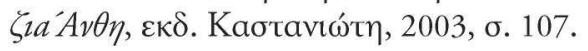

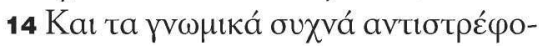

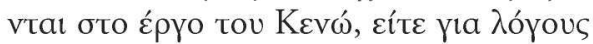

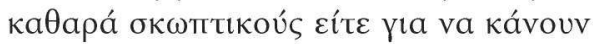

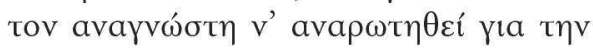

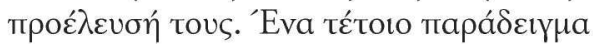

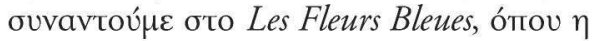

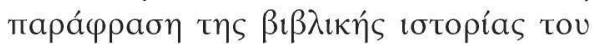

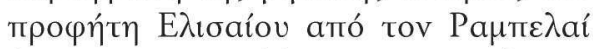

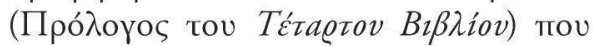

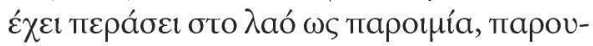

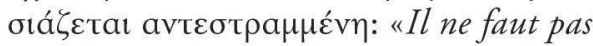
jeter le manche après la cognée», av'í tou

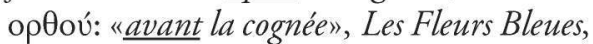

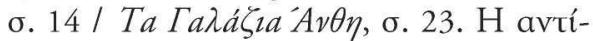

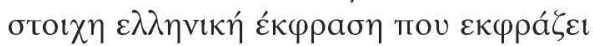

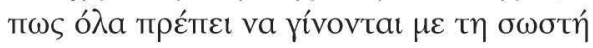

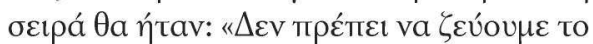

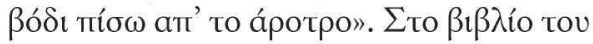

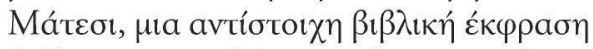

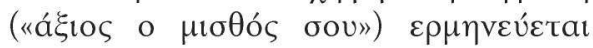

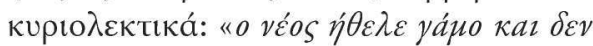

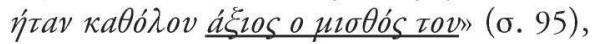

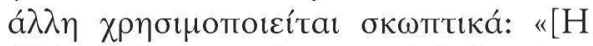

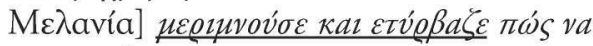

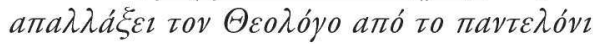

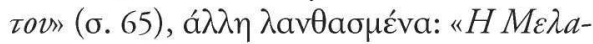

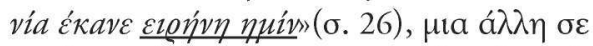

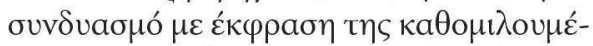

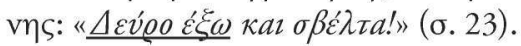

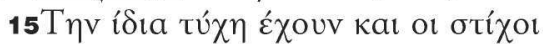

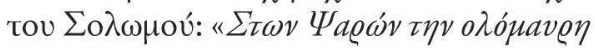

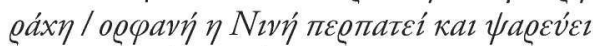

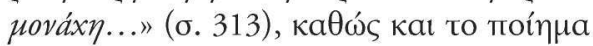

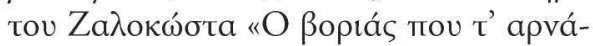

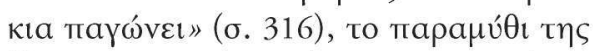

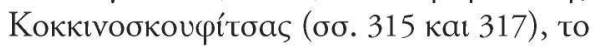

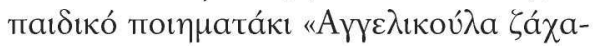

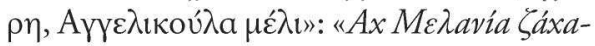

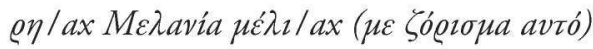

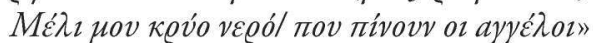
(о. 256), ако́ коú 'Yuvov (!), бто бкото́ tov отоі́⿱一兀

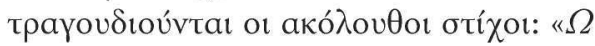

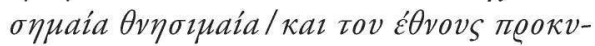

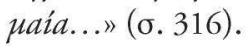

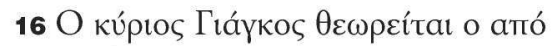

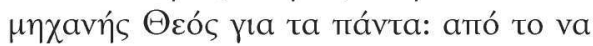

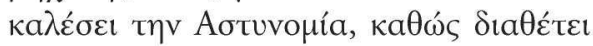

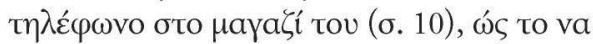

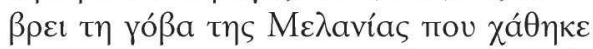

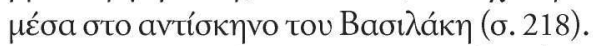

17 Raymond Queneau, Le Chiendent,

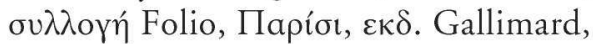
1933 kal 1984.

18 Raymond Queneau, Saint Glinglin,

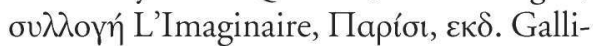
mard, 1948 кaı 1975.

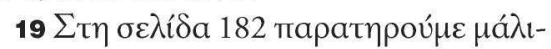

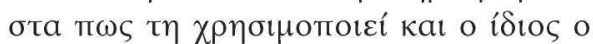

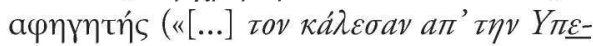

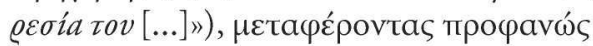

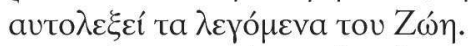

20 Queneau, Zazie dans le métro: «E $\beta a-$

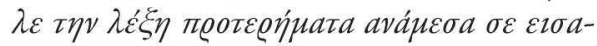

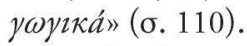

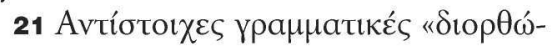

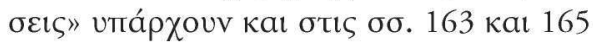
tov $\beta$ i $\beta$ íou.

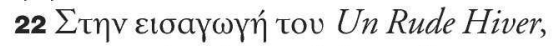

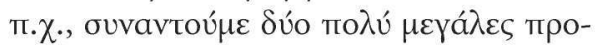

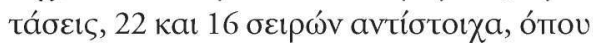

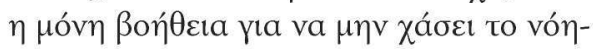

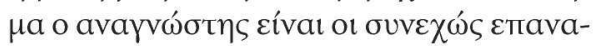

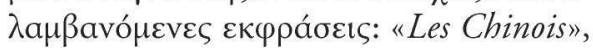

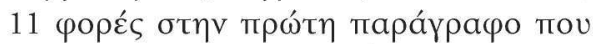

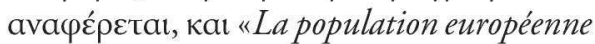

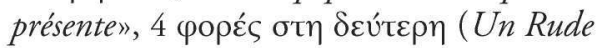
Hiver, бо. 7-9).

23 Queneau, Zazie dans le métro, o. 105. 24 Queneau, Un Rude Hiver, $\sigma .15$. 
$25 \sum$ to ísı, б. 45.

26 Queneau, Zazie dans le métro, o. 35,

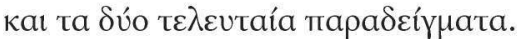

$27 \sum$ to í́iı, б. 121.

$28 \sum$ to í

29 Queneau, Les Fleurs Bleues, o. 160.

so Raymond Queneau, Journal Intime de Sally Mara, oto Quvres complètes de

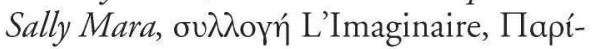
$\sigma \iota, \varepsilon \kappa \delta$. Gallimard, 1962, б. 85.

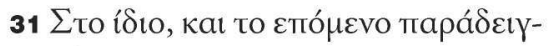
$\mu a, \sigma .348$.

$32 \Sigma$ to í́io, o. 33.

33 Queneau, Les Fleurs Bleues, б. 202.

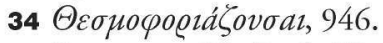

35 Queneau, Un Rude Hiver, o. 89

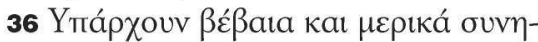

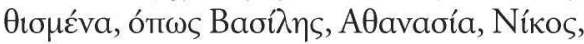
¿oфákı, к.á.

37 Raymond Queneau, Le Dimanche

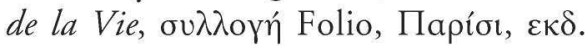
Gallimard, 1952.

38 Queneau, Chêne et chien, o. 48. $\Sigma \varepsilon$

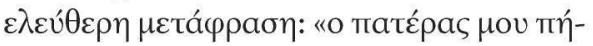

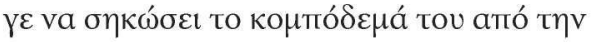

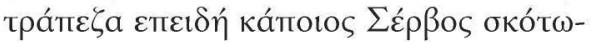

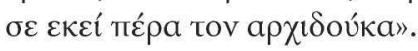

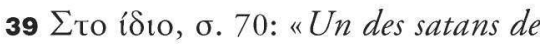
l'Univers [...] porte le manteau de Dieu».

40 Queneau, Zazie dans le métro $($ $\mathrm{H}$

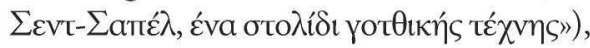
б. 123.

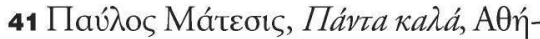

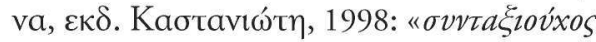

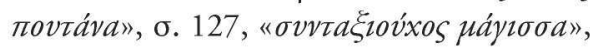
б. 62.

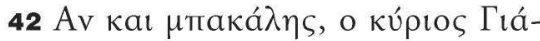

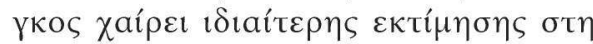

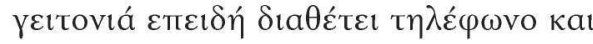

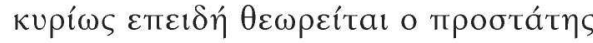

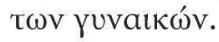

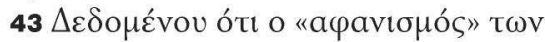

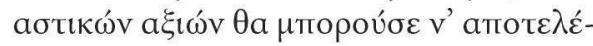

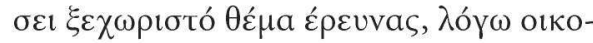

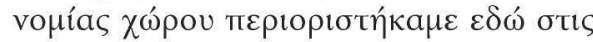

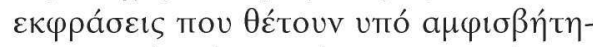

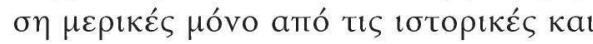

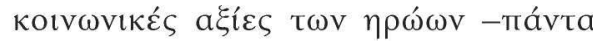

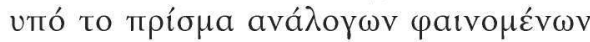

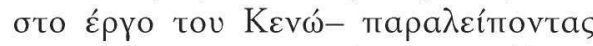

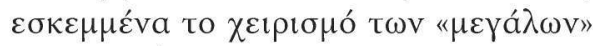

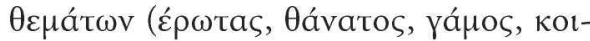

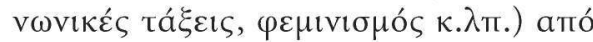
tous ouүYрачвíc. 


\section{S O M M A I R E}

LISA MAMAKOUKA-KouKOUVINOU: L'écho des choix langagiers de Raymond Queneau dans les «erreurs» linguistiques et expressives de Panta kala de Pavlos Matessis

'étude comparée de Panta kala de Pavlos Matessis et de l'œuvre de Raymond Queneau révèle une parenté significative, tant dans le domaine des choix langagiers que dans celui de la vision du monde des deux auteurs. Dans un premier temps ont été repérées deux catégories majeures d'«erreurs» dans le maniement de la langue: a) Celles ayant affaire à la dimension ludique des textes des deux auteurs, notamment les erreurs qui relèvent de l'orthographe, la grammaire, la syntaxe, les jeux de mots, l'usage des clichés, les néologismes, l'onomatopée, l'usage erroné de termes étrangers, le mélange des registres etc., et b) Celles qui servent de "projectiles» dans le cadre de la polémique des deux écrivains contre les valeurs historiques, sociales, religieuses, politiques, etc. qui constituent les fondements de la société de petits bourgeois qui forme le cadre habituel des romans de Matessis et Queneau. Dans un deuxième temps, ces décalages langagiers ont été valorisés par leur intégration dans un parti pris commun des deux romanciers, celui de dévoiler, plus qu'un monde en mutation constante, un monde en décomposition. 